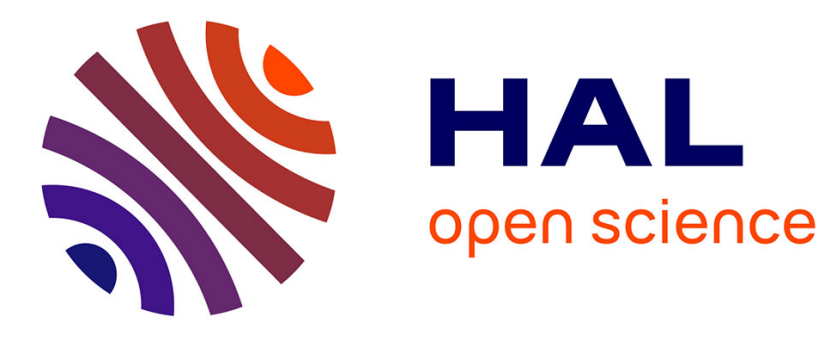

\title{
Mechanistic Insight into Metal Ion-Catalyzed Transamination
}

Robert Josef Mayer, Harpreet Kaur, Sophia Rauscher, Joseph Moran

\section{To cite this version:}

Robert Josef Mayer, Harpreet Kaur, Sophia Rauscher, Joseph Moran. Mechanistic Insight into Metal Ion-Catalyzed Transamination. Journal of the American Chemical Society, 2021, 143 (45), pp.1909919111. 10.1021/jacs.1c08535 . hal-03468111

\section{HAL Id: hal-03468111 https://hal.science/hal-03468111}

Submitted on 6 Dec 2021

HAL is a multi-disciplinary open access archive for the deposit and dissemination of scientific research documents, whether they are published or not. The documents may come from teaching and research institutions in France or abroad, or from public or private research centers.
L'archive ouverte pluridisciplinaire HAL, est destinée au dépôt et à la diffusion de documents scientifiques de niveau recherche, publiés ou non, émanant des établissements d'enseignement et de recherche français ou étrangers, des laboratoires publics ou privés. 


\title{
Mechanistic Insight into Metal lon-Catalyzed Transamination
}

\author{
Robert J. Mayer, ${ }^{\ddagger}$ Harpreet Kaur $₫$ Sophia A. Rauscher and Joseph Moran* \\ University of Strasbourg, CNRS, ISIS UMR 7006, 67000 Strasbourg, France
}

\begin{abstract}
Several classes of biological reactions that are mediated by an enzyme and a co-factor can occur, to a slower extent, not only without the enzyme but even without the co-factor, under catalysis by metal ions. This observation has led to the proposal that metabolic pathways progressively evolved from using inorganic catalysts to using organocatalysts of increasing complexity. Transamination, the biological process by which ammonia is transferred between amino acids and keto acids, has a mechanism that has been well studied under enzyme/co-factor catalysis and under co-factor catalysis, but the metal ion-catalyzed variant was generally studied mostly at high temperatures $\left(70-100^{\circ} \mathrm{C}\right)$, and the details of its mechanism remain unclear. Here, we investigate which

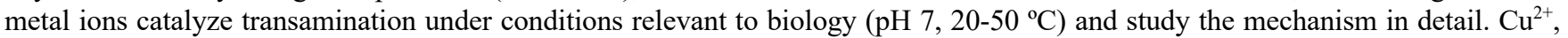
$\mathrm{Ni}^{2+}, \mathrm{Co}^{2+}$ and $\mathrm{V}^{5+}$ were identified as the most active metal ions under these constraints. Kinetic, stereochemical and computational studies illuminate the mechanism of the reaction. $\mathrm{Cu}^{2+}$ and $\mathrm{Co}^{2+}$ are found to predominantly speed up the reaction by stabilizing a key imine intermediate. $\mathrm{V}^{5+}$ is found to accelerate the reaction by increasing the acidity of the bound imine. $\mathrm{Ni}^{2+}$ is found to do both to a limited extent. These results show that direct metal ion-catalyzed amino group transfer is highly favored even in the absence of cofactors or protein catalysts under biologically compatible reaction conditions.
\end{abstract}

\section{Introduction}

It has been known for nearly 80 years that some biological enzyme-catalyzed reactions still occur without enzymes, under catalysis by metal ions. ${ }^{1,2}$ Similarly, many biological reactions co-catalyzed by enzymes and co-factors still occur with only the co-factor as catalyst, ${ }^{3}$ or even under catalysis by metal ions alone. Recently, analogues of entire metabolic pathways, or fragments thereof, have been found to occur under metal or metal ion catalysis, ${ }^{4}$ including the Krebs or reverse Krebs cycles, ${ }^{5}$ the acetyl CoA pathway, ${ }^{6}$ glycolysis and the pentose phosphate pathway, ${ }^{7}$ and gluconeogenesis. ${ }^{8}$ These observations support proposals that precursors to some core metabolic pathways emerged under inorganic catalysis and were later refined by organocatalysis from co-factors and eventually, by enzymes. ${ }^{9}$ However, there is no example of a metabolic reaction for which all three levels of catalytic complexity (1. metal ion, 2. co-factor with or without metal ions, and 3. co-factor + enzyme) are demonstrated and mechanistically understood under biological conditions, making it difficult to appreciate how such an evolutionary progression might have occurred within biochemistry. Furthermore, the precise role of metal ions in promoting reactions of metabolic pathways has largely been overlooked in previous studies. ${ }^{4-8}$

One class of metabolic reaction that might serve as an illustrative example is transamination, the process by which ammonia is transferred between amino acids and $\alpha$-keto acids. Once ammonia flows into metabolism through the reductive amination of $\alpha$-ketoglutarate to give glutamate, several important amino acids are biosynthesized by transamination with $\alpha$-keto acids, many of which are intermediates of the Krebs cycle or the glyoxylate cycle. For example, transamination with glyoxylate, pyruvate, and oxaloacetate gives glycine, alanine, and aspartic acid, respectively (Figure 1A).${ }^{10}$ In biology, transamination reactions are catalyzed by a combination of a co-factor, pyridoxal phosphate (PLP), and an enzyme, a transaminase (Figure 1B). ${ }^{11}$ However, it is well established that transamination reactions still happen without enzymes, catalyzed by PLP with or without metals, and the mechanism of this process has been the subject of a number of studies. ${ }^{12}$ Non-enzymatic transamination can even occur without PLP, under catalysis by metal ions alone (particularly $\mathrm{Al}^{3+}, \mathrm{Fe}^{3+}, \mathrm{Cu}^{2+}$ ), ${ }^{13}$ and to a much more limited extent, without any catalyst at all. ${ }^{14}$ Beside studies on transamination within a biochemical context, non-enzymatic transamination reactions have found application in the asymetric synthesis of amino acids using tailored organocatalysts, ${ }^{15,16}$ or the combination of organocatalysts and metal ions. ${ }^{17}$ Recently, $\mathrm{Cu}^{2+}$ or $\mathrm{Ni}^{2+}$-catalyzed transamination of the $\mathrm{N}$-terminal sites of proteins with glyoxylate was also proposed as a method for the formation of protein bioconjugates. ${ }^{18}$

Understanding the mechanism, scope and influence of various metals on non-enzymatic metal ion-catalyzed transamination under biological conditions could allow transamination to be used as a representative case study for the early evolution of co-factors and metabolic pathways. It could also help assess whether transamination might have played a role in the potentially pre-enzymatic origins of biological amino acid metabolism, as metal ions are ubiquitous in nearly all environments. ${ }^{19}$

In the context of transamination between biochemical substrates, mechanistic studies have been carried out on the slow catalyst-free reaction, which is limited to glyoxylate, ${ }^{20}$ and much is known about the stoichiometric formation of metalimine complexes. ${ }^{21}$ However, following the original exploratory studies carried out in the 1950s mostly under high temperatures $\left(70-100{ }^{\circ} \mathrm{C}\right),{ }^{13 \mathrm{a}, \mathrm{b}}$ little work has been done on the overall mechanism of transamination solely under catalysis by metal ions. Here, we re-evaluated a wide variety of metal ions as catalysts under plausible biological conditions ( $\left.\mathrm{pH} 7,20-50{ }^{\circ} \mathrm{C}\right)$ and identifed $\mathrm{Cu}^{2+}, \mathrm{Ni}^{2+}, \mathrm{Co}^{2+}$, and $\mathrm{V}^{5+}$ as the most viable 
catalysts. We then performed detailed kinetic, stereochemical, and computational studies to elucidate the mechanism and to understand the particularities of each metal.

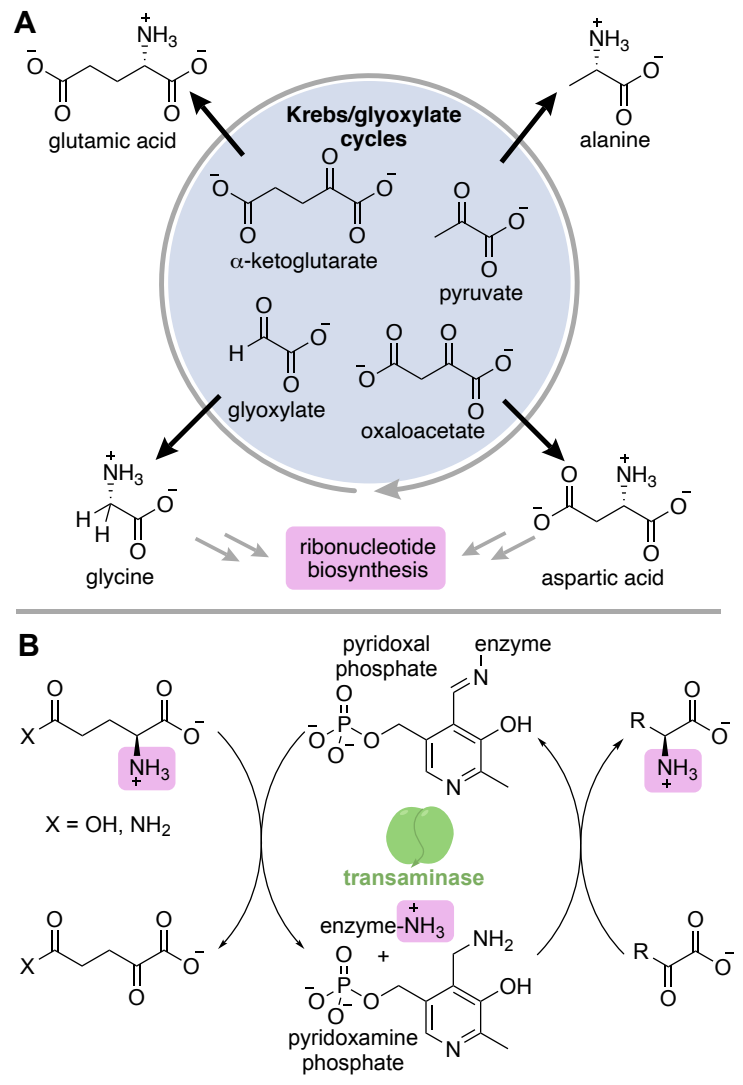

Figure 1. (A) Biosynthesis of amino acids from glyoxylate and the intermediates of the Krebs cycle. (B) Enzymatic transamination mediated by pyridoxal phosphate (PLP) as co-factor.

\section{Results and Discussion}

\section{Products of Transamination Reactions}

Identification of Reaction Conditions. Initially, we studied the effects of $20 \mathrm{~mol} \%$ of chloride and sulfate salts of various transition metals on the transamination reaction between glyoxylate and glutamic acid to yield glycine and $\alpha$-ketoglutarate at $23{ }^{\circ} \mathrm{C}$ and $\mathrm{pH} 7$ (Table 1 ). To avoid necessary $\mathrm{pH}$ adjustments for screening experiments, $1 \mathrm{M}$ phosphate buffer at $\mathrm{pH} 7$ was used as solvent. The Gibbs free energy of the reaction was estimated to be $\Delta \mathrm{G}^{0}=-14.9 \mathrm{~kJ} \mathrm{~mol}^{-1}$ based on reported enzyme kinetics (see the Supporting Information for details). ${ }^{22,23}$ Thus, at a concentration of $30 \mathrm{mM}$ of glyoxylate and $45 \mathrm{mM}$ of glutamic acid, $29.8 \mathrm{mM}$ glycine should form if the equilibrium establishes without any side reactions. We found that the transamination reaction of $30 \mathrm{mM}$ glyoxylate with 1.5 equiv glutamic acid yields glycine in $0.3-91 \%$ yield as determined by quantitative ${ }^{1} \mathrm{H}$ NMR spectroscopy after removal of the metals with the ion-exchange resin Chelex ${ }^{\circledR}$ (Table 1). The lower yields of glycine compared to the thermochemical prediction were attributed to the competing decomposition of glyoxylate in the presence of some metals as well as side reactions, e.g., the aldol reaction of glyoxylate with in-situ formed $\alpha$-ketoglutarate (see Figure S1-2 for representative NMR spectra). ${ }^{13 \mathrm{f}}$ The most efficient catalysts for the transamination reaction at
$23{ }^{\circ} \mathrm{C}$ and $\mathrm{pH} 7$ are $\mathrm{Ni}^{2+}, \mathrm{Cu}^{2+}, \mathrm{V}^{5+}$, and $\mathrm{Co}^{2+}$ (entries 1-4). ${ }^{24}$ However, many other transition metals still show a significant catalytic activity (entries 5-12), surpassing the uncatalyzed background reaction (entry 21).

Table 1. Reaction of Glyoxylate $(30 \mathrm{mM})$ and Glutamic Acid (1.5 equiv) in the Presence of $20 \mathrm{~mol} \%$ of Different Metal Salts at $23{ }^{\circ} \mathrm{C}\left(1 \mathrm{M}\right.$ Phosphate Buffer, pH 7, 24 h). ${ }^{\mathrm{a}}$

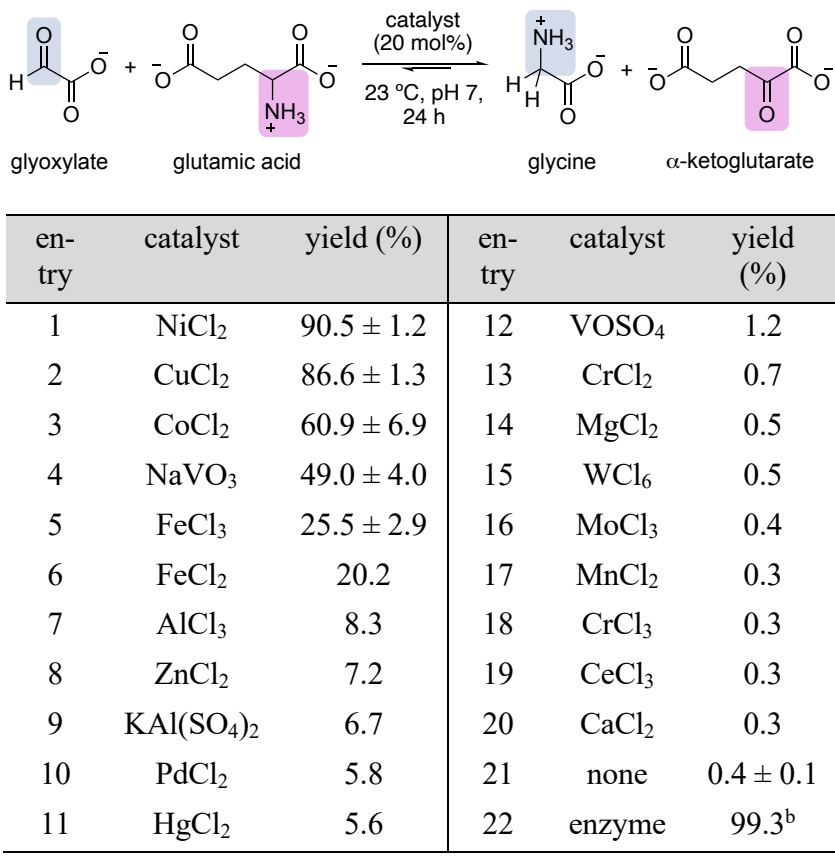

${ }^{\text {a }}$ Yields were determined by quantitative ${ }^{1} \mathrm{H}$ NMR spectroscopy with dimethyl sulfone as an internal standard after removing metal ions with Chelex ${ }^{\circledR}$. Errors correspond to standard deviations (see Supporting Information for details). ${ }^{b}$ Maximum possible yield considering the Gibbs free energy of the reaction, the concentrations of the reactants and the temperature. ${ }^{22,23}$

Next, we studied whether the reaction conditions identified for the transamination of glyoxylate to glycine are suitable for the transamination of pyruvate with glutamic acid to yield alanine and $\alpha$-ketoglutarate. Transamination with glutamic acid to pyruvate is thermodynamically far less favored than to glyoxylate, as evident from the only slightly exergonic Gibbs free energy of the reaction with $\Delta \mathrm{G}^{0}=-1.04 \mathrm{~kJ} \mathrm{~mol}^{-1}$. $^{22}$ Accordingly, from $30 \mathrm{mM}$ pyruvate and $45 \mathrm{mM}$ glutamic acid, a maximum of $19.8 \mathrm{mM}$ alanine ( $66 \%$ yield) should form if the equilibrium can establish without side reactions. However, the reaction with $20 \mathrm{~mol} \% \mathrm{Cu}^{2+}, \mathrm{Co}^{2+}, \mathrm{Ni}^{2+}$, or $\mathrm{V}^{5+}$ as catalyst yielded only small amounts of alanine $(<2 \%)$ after $24 \mathrm{~h}$ at room temperature. 
Table 2. Transamination Reaction of Pyruvate $(30 \mathrm{mM})$ with Glutamic Acid (45 mM) at $23^{\circ} \mathrm{C}$ and $50^{\circ} \mathrm{C}(1 \mathrm{M}$ Phosphate Buffer, pH 7). ${ }^{\mathrm{a}}$

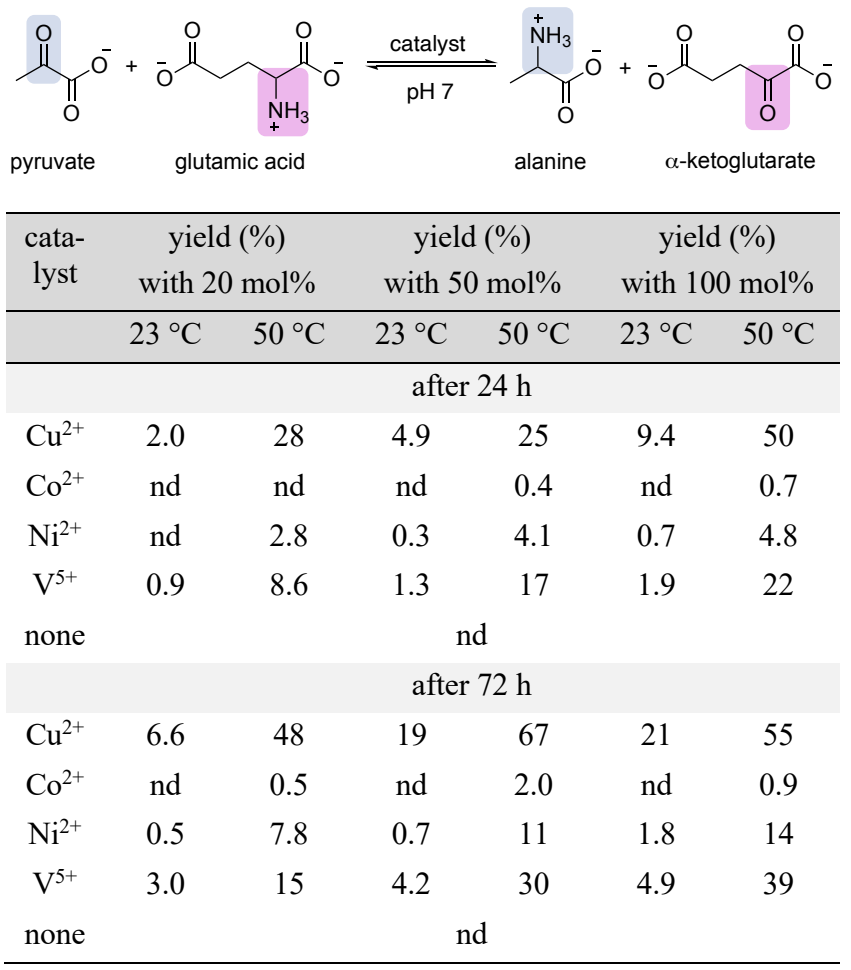

${ }^{\text {a }}$ Yields were determined by quantitative ${ }^{1} \mathrm{H}$ NMR spectroscopy with dimethyl sulfone as an internal standard after removing metal ions with Chelex ${ }^{\circledR}$ (see the Supporting Information for details). nd: Not detected (detection limit $\approx 0.3 \%$ alanine).

Increasing the amount of catalyst and the reaction time resulted in higher conversion: With $50 \mathrm{~mol} \% \mathrm{Cu}^{2+}, 67 \%$ alanine formed after $72 \mathrm{~h}$ at $50{ }^{\circ} \mathrm{C} . \mathrm{V}^{5+}$ and $\mathrm{Ni}^{2+}$ yields less alanine $(30 \%$ and $11 \%$ at $50{ }^{\circ} \mathrm{C}$ and $72 \mathrm{~h}$, respectively) and $\mathrm{Co}^{2+}$ showed little conversion. The results in Table 2 generally parallel those of Mix, who found that $\mathrm{Cu}^{2+}$ was the most efficient catalyst in the transamination of pyruvate with various amine donors at $70^{\circ} \mathrm{C}$ (based on the yield after $2 \mathrm{~h}, \mathrm{pH} 7$ ). ${ }^{13 \mathrm{~b}}$

Transamination Reactions with Other Substrates. We next investigated the reactions between other amine donors and keto acids. $\mathrm{Cu}^{2+}$ was used as catalyst due to its strong performance in the reactions of glutamic acid with both glyoxylate and pyruvate. Thus, glyoxylate, pyruvate, and $\alpha$-ketoglutarate $(30 \mathrm{mM})$ were reacted with different amino acids $(45 \mathrm{mM})$ in the presence of $20 \mathrm{~mol} \% \mathrm{CuCl}_{2}$ at $50{ }^{\circ} \mathrm{C}$ for $72 \mathrm{~h}$. Again, thermochemistry is the factor deciding the feasibility of a specific transformation and enzymatic data can be used to gauge the extent to which a specific combination will react. However, it must be acknowledged that the position of the equilibria will also be affected by the $20 \mathrm{~mol} \%$ of catalyst present due to formation of metal-chelates. Compared to enzyme-catalyzed transaminations, the metal-catalyzed reactions were found in most cases to reach lower yields of products compared to the enzymatic reaction. Table 3 summarizes reported Gibbs free energies for some combinations of substrates and the observed yield of the transamination product under metal catalysis. While oxaloacetate could be a possible substrate for transamination reactions to yield aspartic acid, we found that it readily undergoes decomposition to pyruvate in the presence of metal ions under the reaction conditions. ${ }^{1}$ Pyruvate, in turn, undergoes transamination to yield alanine. Accordingly, we did not detect the formation of aspartic acid.

In line with the reported thermochemistry, transamination reactions with glyoxylate generally yield significant amounts of glycine with glutamic acid, glutamine, alanine or aspartic acid. Slightly lower concentrations of glycine were observed when serine was used as amine donor. With pyruvate as substrate, only small amounts of alanine $(5.7 \mathrm{mM})$ were formed when using glycine as amine donor, in line with the unfavorable thermochemistry of the reaction.

Table 3. Comparison of Theoretical and Experimentally Obtained Concentrations for the $\left.\mathrm{Cu}^{2+}-\mathrm{Catalyzed}_{(20} \mathrm{mol} \%\right) \mathrm{Trans}-$ amination of Keto Acids (KA, $30 \mathrm{mM}$ ) and Amino Acids (AA, $45 \mathrm{mM}$ ) at $50{ }^{\circ} \mathrm{C}$ (1 M Phosphate Buffer, pH 7, 72 h).

\begin{tabular}{|c|c|c|c|c|c|c|c|c|c|c|}
\hline$\underbrace{\mathrm{NH}_{3}}_{+}$ & O & O & & $\left.\right|_{0} ^{\stackrel{+}{N} H_{3}}$ & $\underbrace{O}_{0}$ & & $\mathrm{H}_{3}$ & O & $\mathrm{O}$ & $\stackrel{+}{\mathrm{N}} \mathrm{H}_{3}$ \\
\hline amino acid & R of amino acid (AA) & $\begin{array}{c}\Delta \mathrm{G}^{0, \mathrm{a}} \\
/ \mathrm{kJ} \mathrm{mol}^{-1}\end{array}$ & $\begin{array}{c}\text { [glycine }_{\text {enzym. }}{ }^{\mathrm{b}} \\
/ \mathrm{mM} \\
\end{array}$ & 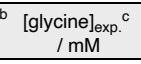 & $\begin{array}{c}\Delta \mathrm{G}^{0, \mathrm{a}} \\
/ \mathrm{kJ} \mathrm{mol}^{-1} \\
\end{array}$ & $\begin{array}{c}\text { [alanine }_{\text {enzym. }}{ }^{\mathrm{b}} \\
/ \mathrm{mM}\end{array}$ & $\begin{array}{c}\text { [alanine }]_{\text {exp. }}{ }^{\mathrm{c}} \\
/ \mathrm{mM}\end{array}$ & $\begin{array}{c}\Delta \mathrm{G}^{0, \mathrm{a}} \\
/ \mathrm{KJ} \mathrm{mol}^{-1} \\
\end{array}$ & $\begin{array}{c}\text { [glutamate }_{\text {enzym. }}{ }^{\mathrm{b}} \\
/ \mathrm{mM}\end{array}$ & 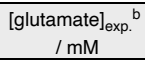 \\
\hline glycine & & 0 & ident. & ident. & +13.9 & 2.6 & 5.7 & +14.9 & 2.2 & 5.2 \\
\hline alanine & & -13.9 & 29.7 & 22.0 & 0 & ident. & ident. & +1.04 & 16.3 & 15.5 \\
\hline glutamic acid & & -14.9 & 29.8 & 26.2 & -1.04 & 19.7 & 15.5 & 0 & ident. & ident. \\
\hline glutamine & & $d$ & d & 24.7 & d & d & 5.6 & d & d & 2.7 \\
\hline aspartic acid & & -10.2 & 28.8 & $\begin{array}{c}19.7 \\
15.2(\text { alanine })^{\mathrm{e}}\end{array}$ & +3.69 & 12.2 & $29.8^{e}$ & +4.73 & 10.7 & $\begin{array}{c}9.0 \\
5.7\left(_{\text {alanine })^{\mathrm{e}}}\right.\end{array}$ \\
\hline serine & $\mathrm{HO}^{\widehat{Y}}$ & -10.8 & 29.1 & 9.2 & +3.09 & 13.1 & 1.0 & +4.13 & 11.5 & $<1$ \\
\hline
\end{tabular}

${ }^{a}$ Experimental thermochemistry from refs. 22,23 or derived from thermodynamic cycles as shown in the Supporting Information. ${ }^{\mathrm{b}}$ Calculated based on the mass action law, the reactant concentrations, and the equilibrium constants (at $298 \mathrm{~K}$ ) obtained via the relation $\Delta G^{0}=-$ $\mathrm{RT} \ln K$ using $\mathrm{T}=323 \mathrm{~K}$ (values of $K$ were not temperature corrected). ${ }^{\mathrm{c}}$ Concentrations were determined by quantitative ${ }^{1} \mathrm{H}$ NMR spectroscopy with dimethyl sulfone as an internal standard after removing metal ions with Chelex ${ }^{\circledR}$. ${ }^{\mathrm{d}}$ Experimental thermochemistry not available. e Alanine is formed due to transamination to in-situ formed pyruvate. 
With glutamic acid, glutamine, or aspartic acid as amine donors, 5.6 - $29.8 \mathrm{mM}$ of alanine were obtained which were highest for aspartic acid due to above-mentioned side reaction. Similar to the transamination of pyruvate with glycine, only small amounts of glutamic acid form in the reaction of $\alpha$-ketoglutarate with glycine. The formation of significant amounts of glutamic acid in the reactions of $\alpha$-ketoglutarate with alanine, glutamine, and aspartic acid highlights the similar thermochemistry of these reactions. Serine, however, only transaminates to a minor extent to both $\alpha$-ketoglutarate and pyruvate.

\section{Reaction Kinetics}

Transamination Reactions of Glyoxylate. The kinetics of the transamination reactions of glyoxylate and glutamic acid were studied in aqueous phosphate buffer at $\mathrm{pH} 7$ by ${ }^{1} \mathrm{H}$ NMR spectroscopy at $23{ }^{\circ} \mathrm{C}$ (Figure 2). The kinetics of the uncatalyzed reaction of equimolar amounts of glyoxylate and glutamic acid $(30 \mathrm{mM})$ showed a first-order rate constant $k_{\mathrm{obs}}=$ $(2.89 \pm 0.02) \times 10^{-7} \mathrm{~s}^{-1}$, which corresponds to a half-life of $t_{1 / 2} \approx 28$ days. Next, we tested the effect of metal ions on the reaction rates which were identified as most active in our initial screening. In contrast to most other investigated metal ions, the diamagnetic nature of $\mathrm{V}^{5+}$ allows the use of multinuclear NMR spectroscopy to follow the reaction progress. In the presence of
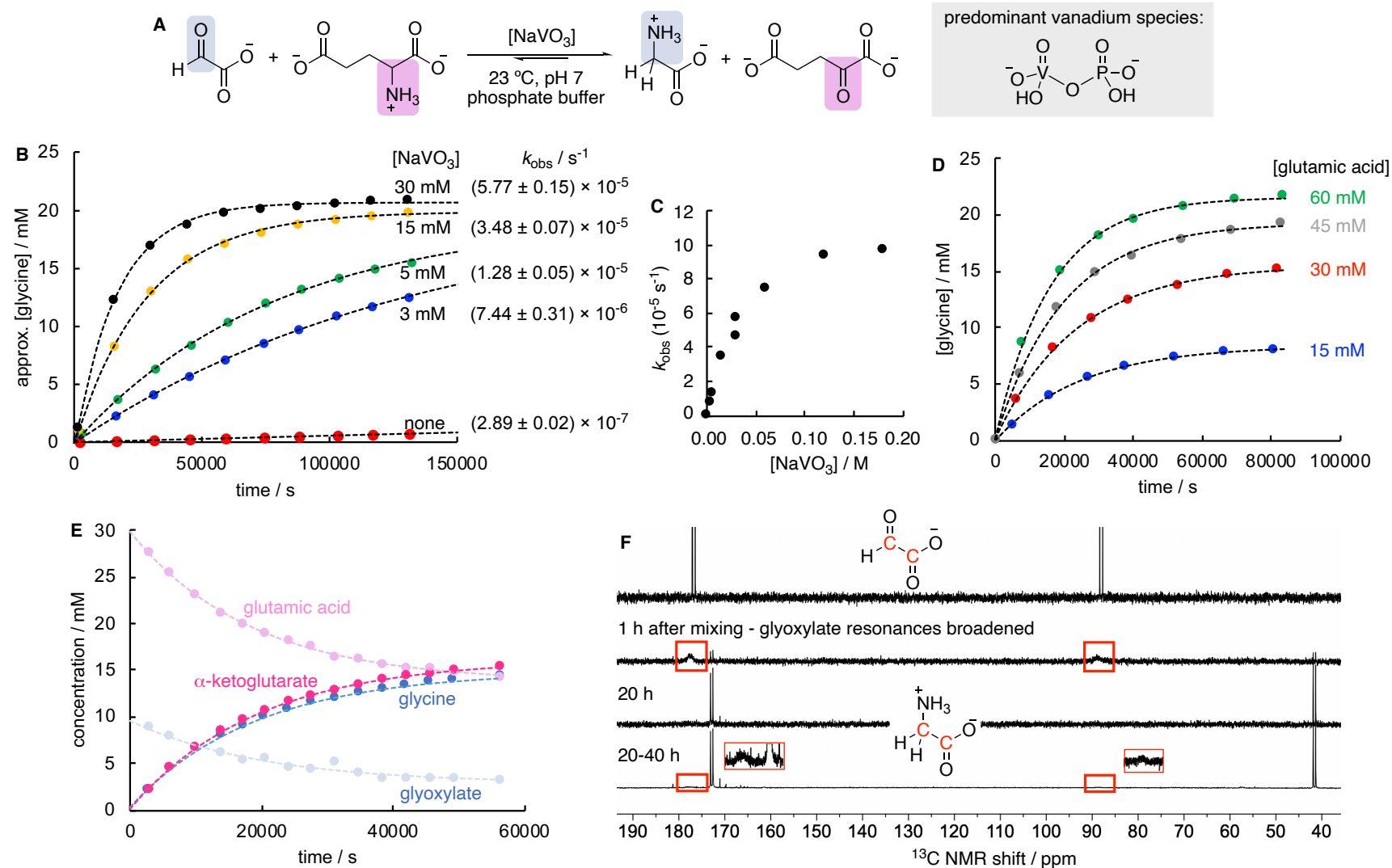

Figure 2. (A) Vanadate-catalyzed transamination reaction of glyoxylate with glutamic acid. (B) ${ }^{1} \mathrm{H}$ NMR kinetics (approximate concentrations from qualitative NMR measurements) of the reaction of glyoxylate $(30 \mathrm{mM})$ with glutamic acid $(30 \mathrm{mM})$ in the presence of different amounts of $\mathrm{NaVO}_{3}$ and (C) dependency of observed rate constants $k_{\mathrm{obs}}$ on the concentration of vanadate. (D) ${ }^{1} \mathrm{H}$ NMR kinetics (concentrations from quantitative NMR measurements) of the reaction of glyoxylate $(30 \mathrm{mM})$ with different amounts of glutamic acid $(15-60 \mathrm{mM})$ in the presence of $\mathrm{NaVO}_{3}(30 \mathrm{mM})$. (E) Concentrations of all main species for the reaction ${ }^{13} \mathrm{C}$-labeled glyoxylate $(30 \mathrm{mM})$ with glutamic acid $(30$ $\mathrm{mM})$ in the presence of $\mathrm{NaVO}_{3}(30 \mathrm{mM})$. (F) Quantitative ${ }^{13} \mathrm{C} \mathrm{NMR}$ spectra of the reaction of fully ${ }^{13} \mathrm{C}$ labeled glyoxylate (30 mM) with glutamic acid $(30 \mathrm{mM})$ in the presence of $\mathrm{NaVO}_{3}(30 \mathrm{mM})$ at different time points. Reactions in (B), (C), (E) and (F) were performed in $0.92 \mathrm{M}$ phosphate buffer, (D) in $1 \mathrm{M}$ phosphate buffer, all at $\mathrm{pH} 7,23{ }^{\circ} \mathrm{C}$. Dashed lines correspond to the fitted kinetic curves (see the Supporting Information). phosphate ions at $\mathrm{pH} 7$, the predominant vanadium species in phosphate and vanadate, as evident from the ${ }^{51} \mathrm{~V}$ NMR spectra (Figure 2A; see also the Supporting Information and Figure S5

To study the nature of the vanadium species involved in the

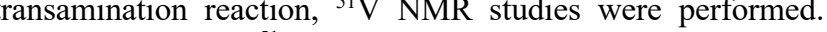
of broad resonances with shifts between -510 and $-540 \mathrm{ppm}$ (Supporting Information, Figure S6-8). The relative intensity of of amine and keto-acids relative to vanadate, suggesting an equilibrium process. ${ }^{51} \mathrm{~V}$ NMR shifts of similar magnitude were tion. ${ }^{26}$ Accordingly, 2,6-dicarboxypyridine, which is expected to bind analogously to the imine formed from the condensation of keto- and amino acids, produced a similar ${ }^{51} \mathrm{~V}$ NMR shift $(-$ $30 \mathrm{ppm})$ in the presence of $\mathrm{NaVO}_{3}$. Therefore, the ${ }^{51} \mathrm{~V} \mathrm{NMR}$ resonances observed during the reaction are expected to be due to the formation of imine-vanadate chelates. 
Next, ${ }^{1} \mathrm{H}$ NMR spectroscopy was used to follow the timedependent concentrations of amino and keto acids. The increase in glycine concentration was found to follow first-order kinetics to afford the rates $k_{\text {obs }}\left(\mathrm{s}^{-1}\right)$ (Figure 2B). The first order rate constants $k_{\mathrm{obs}}$ correspond to the rate constants for the approach of the reaction to equilibrium with $k_{\text {obs }}=k_{\text {forward }}+k_{\text {reverse. }}$. As the equilibrium for the reaction of glyoxylate with glutamic acid is significantly exergonic $\left(\Delta \mathrm{G}^{0}=-14.9 \mathrm{~kJ} \mathrm{~mol}^{-1}, K=414\right)$, the rates $k_{\text {obs }}$ correspond closely to $k_{\text {forward }}$ (see the Supporting Information for a detailed discussion). Compared to the uncatalyzed reaction, the presence of $0.0030 \mathrm{M}$ vanadate (corresponding to $10 \mathrm{~mol} \%$ ) increased the reaction rate by a factor of 26 , while with an equimolar concentration of vanadate, the reaction proceeds 200 times faster. However, further increase of the vanadate concentration up to $0.18 \mathrm{M}$ (corresponding to $600 \mathrm{~mol} \%$ ) did not result in a linear increase of the reaction rate, indicating complete binding of the substrate to the catalyst (Figure 2C).

As evident from Figure 2B, the concentration of glycine (ca. $20 \mathrm{mM}$ ) is significantly lower than would be expected from the reported thermochemistry given that the reactants were used in $30 \mathrm{mM}$ concentration. This observation was corroborated by following the kinetics of the reaction of glyoxylate in the presence of $\mathrm{NaVO}_{3}$ with different concentrations of glutamic acid (Figure 2D). The yield of glycine increased with higher concentrations of glutamic acid, but the conversion ceased after approximately $20 \mathrm{~h}$, leaving unreacted glutamic acid behind. Throughout the reaction, the mass balance of glutamic acid and $\alpha$-ketoglutarate add up to the expected concentrations. As expected, the concentration of $\alpha$-ketoglutarate approximately equals the one of glycine which forms with identical reaction rate. However, the disappearance of glyoxylate could not be quantified by ${ }^{1} \mathrm{H}$ NMR spectroscopy due to proximity of the resonance of glyoxylate hydrate with that of water. Therefore, doubly ${ }^{13} \mathrm{C}$-labeled glyoxylate, whose doublet resonance $\left(J_{1 \mathrm{H}}-\right.$ ${ }_{13 \mathrm{C}}=166 \mathrm{~Hz}$ ) is sufficiently separated from the water resonance, was used as substrate (Figure S9). As illustrated in Figure 2E, the concentration of glyoxylate is consistently lower than expected from the conversion. To identify the fate of glyoxylate, we additionally studied the reaction by quantitative ${ }^{13} \mathrm{C}$ NMR (Figure S10). Shortly after mixing, we observed broadening of the glyoxylate resonances (Figure $2 \mathrm{~F}$ ). Identical broadened ${ }^{13} \mathrm{C}$ resonances were observed when mixing glyoxylate with $\mathrm{NaVO}_{3}$, suggesting the formation of vanadate-glyoxylate complexes (Figure S11-12). At the end of the reaction, most of the ${ }^{13} \mathrm{C}$-labeled material is present as glycine, however the broadened resonance of glyoxylate still remains but is difficult to quantify. We therefore attribute the observed unavailability of glyoxylate during the reaction to the competing formation of vanadate-glyoxylate complexes as well as incorrect integration due to signal broadening. In contrast to previous studies at higher temperatures without metal catalysts, no direct decomposition products of glyoxylate (e.g., to $\mathrm{HCO}_{3}^{-}$, oxalic acid, glycolic acid) were observed. ${ }^{20}$

Next, we investigated the effect of changing the amine donor on the reaction rates. Interestingly, the rate constants for the reactions with glutamic acid, glutamine, or alanine did not differ largely (Figure 3). A faster reaction rate was observed only for aspartic acid, which can be rationalized by the fast subsequent decarboxylation of the reaction product, oxaloacetate. The larger differences in conversion are, therefore, attributed to more pronounced differences in the reaction thermodynamics.

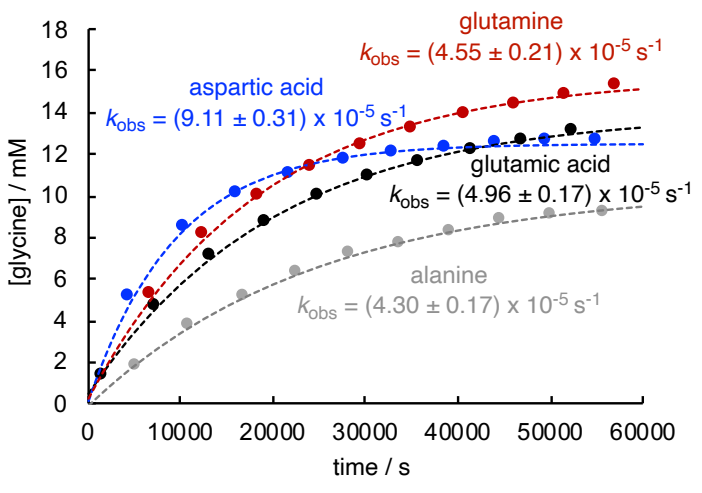

Figure 3. ${ }^{1} \mathrm{H}$ NMR kinetics of the reaction of glyoxylate $(30 \mathrm{mM})$ with different amino acids $(30 \mathrm{mM})$ in the presence of $30 \mathrm{mM}$ $\mathrm{NaVO}_{3}\left(0.92 \mathrm{M}\right.$ phosphate buffer, $\left.\mathrm{pH} 7,23^{\circ} \mathrm{C}\right)$. Dashed lines indicate the fitted kinetic curves (see the Supporting Information).
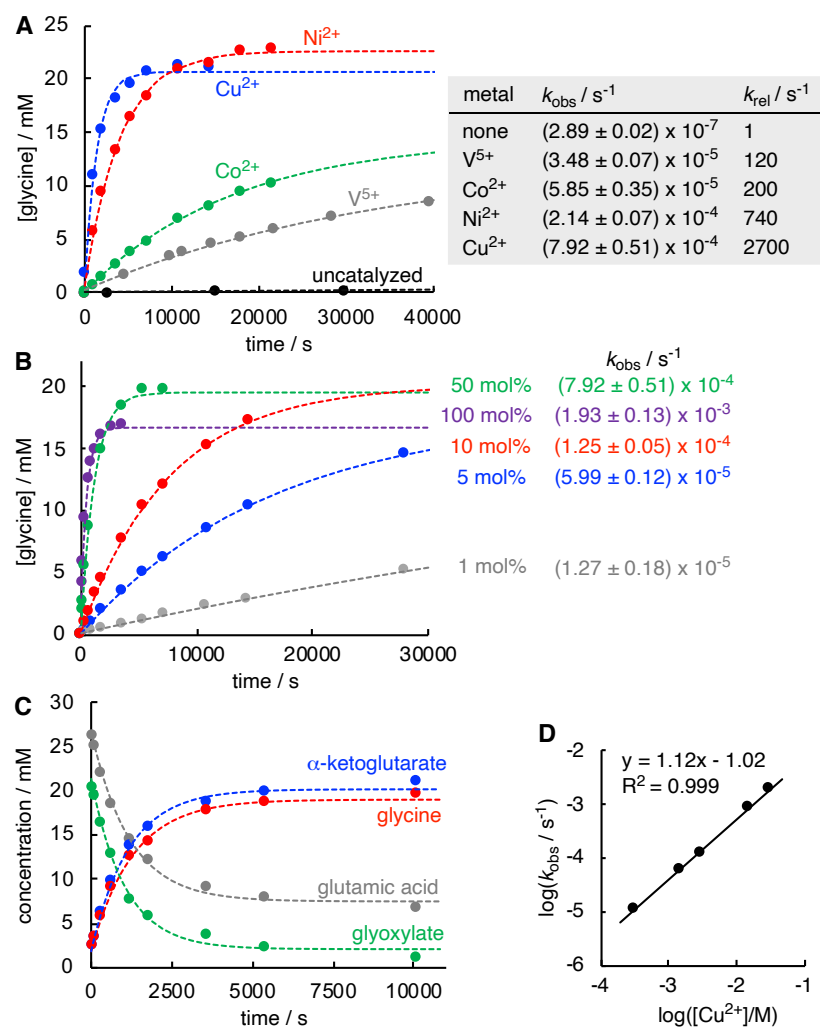

Figure 4. (A) Kinetics of the reaction of glyoxylate $(30 \mathrm{mM})$ with glutamic acid $(30 \mathrm{mM})$ in the presence of catalyst $(15 \mathrm{mM})$ and $(B)$ of the reaction of glyoxylate $(30 \mathrm{mM})$ with glutamic acid $(30 \mathrm{mM})$ in the presence of different amounts of $\mathrm{CuCl}_{2}$ as catalyst. Concentrations were determined by manual sampling/quantitative ${ }^{1} \mathrm{H}$ NMR spectroscopy at $23{ }^{\circ} \mathrm{C}(1 \mathrm{M}$ phosphate buffer, $\mathrm{pH} 7)$. (C) Concentrations of all main species for the reaction of ${ }^{13} \mathrm{C}$-labeled glyoxylate $(30 \mathrm{mM})$ with glutamic acid $(30 \mathrm{mM})$ in the presence of $\mathrm{CuCl}_{2}$ (15 mM); see Figure S13-14 for full NMR spectra. (D) Double-logarithmic correlation to determine the reaction order in $\mathrm{Cu}^{2+}$. Dashed lines in (A-C) indicate the fitted kinetic curves (see the Supporting Information).

As online NMR methods could not be performed in the reactions catalyzed by $\mathrm{Co}^{2+}, \mathrm{Ni}^{2+}$, and $\mathrm{Cu}^{2+}$, reactions were manually sampled. When performed in $\mathrm{pH} 7$ phosphate buffer, the reactions with $\mathrm{Cu}^{2+}, \mathrm{Ni}^{2+}$, and $\mathrm{Co}^{2+}$ are homogeneous when the concentration of the metal is lower than that of the amino acid. 
Otherwise, a precipitate of $\mathrm{M}_{3}\left(\mathrm{PO}_{4}\right)_{2}(\mathrm{M}=\mathrm{Cu}, \mathrm{Ni}, \mathrm{Co})$ is formed. In line with our initial screening results, the relative rate enhancement observed for the transamination reaction of glyoxylate with glutamic acid was found to be $\mathrm{Cu}^{2+}>\mathrm{Ni}^{2+}>\mathrm{Co}^{2+}$ $>\mathrm{V}^{5+}$. Compared to the uncatalyzed reaction, $50 \mathrm{~mol} \%$ of $\mathrm{Cu}^{2+}$ enhances the rate constant for the transamination reaction of glyoxylate with glutamic acid by more than 3 orders of magnitude, while $\mathrm{Ni}^{2+}$ increases the rate by approximately a factor of 740 (Figure 4A). In line with the results from Table 1, the $\mathrm{Ni}^{2+}$ catalyzed reaction is found to be slower than the $\mathrm{Cu}^{2+}$-catalyzed one but yields a higher concentration of glycine.

The presence of just $1 \mathrm{~mol} \%$ of $\mathrm{Cu}^{2+}$ causes transamination to proceed approximately 40 times faster than in the absence of a catalyst (Figure 4B) with the reaction being first order in $\mathrm{Cu}^{2+}$ (Figure 4D). Due to the limited solubility of $\mathrm{Cu}^{2+}$ in phosphate buffer, concentrations higher than $100 \mathrm{~mol} \%$, which would be expected to display saturation behavior similar to that observed with $\mathrm{V}^{5+}$ (Figure 2C), could not be investigated. However, as with $\mathrm{V}^{5+}$ catalysis, the $\mathrm{Cu}^{2+}$-catalyzed reaction does not reach complete conversion due to the apparent unavailability of glyoxylate at the end of the reaction (Figure 4C). Again, no decomposition products of glyoxylate were detected, suggesting the competing formation of metal-glyoxylate complexes, for example.

Finally, we tested the effect of the buffer type and concentration on the reaction kinetics at $\mathrm{pH} 7$. When the $\mathrm{Cu}^{2+}$-catalyzed reaction was performed in $0.1 \mathrm{M}$ phosphate buffer instead of $1 \mathrm{M}$ phosphate buffer, within the error limits identical rate constants for the reaction were observed. Analogously, the rate did not change significantly when the reaction was performed in 0.1 M PIPES buffer, a non-coordinating buffer (see the Supporting Information Tables S39-41 for the individual experiments). ${ }^{27}$

Isotope Effects. To get further insight into the mechanism and the nature of the rate-determining step of the transamination with glyoxylate, the kinetics of the $\mathrm{Cu}^{2+}$ - and $\mathrm{V}^{5+}$-catalyzed reactions were studied using deuterated alanine as substrate (Figure 5). When the reaction of glyoxylate with deuterated glutamic acid was performed in non-deuterated buffer, only the formation of unlabeled glycine was observed, suggesting the mechanism involving deprotonation and subsequent re-protonation by the solvent. These results are in line with the work of Richard et al., who studied the mechanism of the deprotonation of iminium ions formed from the condensation of glycine with carbonyl compounds (e.g., acetone, phenyl glyoxylate, PLP) in buffered $\mathrm{D}_{2} \mathrm{O} .^{28}$

Kinetic isotope effects (KIE) were next investigated. Compared to the reaction with non-deuterated glutamic acid, the use of $\mathrm{d}_{3}$-glutamic acid resulted in a decreased reaction rate and a reduction in conversion (Figure $5 \mathrm{~B} / \mathrm{C}$ ). A comparison of the initial rates suggests a KIE of 4.8 for the $\mathrm{Cu}^{2+}$-catalyzed process. ${ }^{29}$ Analogously, the KIE was determined by ${ }^{1} \mathrm{H}$ NMR kinetics for the $\mathrm{V}^{5+}$-catalyzed reaction as 6.1 (with $100 \mathrm{~mol}_{0} \mathrm{NaVO}_{3}$; see the Supporting Information). Such primary substrate KIEs are in line with a rate-determining deprotonation from $\mathbf{I}$ to $\mathbf{I}^{-}\left(k_{\mathrm{B}-, 1}\right.$, Figure 5D), followed by a fast re-protonation of $\mathbf{I}^{-}$to $\mathbf{I}^{\prime}$ via $k_{\mathrm{BH}, 2}$. In the case of the $\mathrm{Cu}^{2+}$-complex, the assumption of a fast reprotonation via $k_{\mathrm{BH}, 2}$ (as opposed to $k_{\mathrm{BH}, 1}$ to yield $\mathbf{I}$ again) can be justified based on the acidities $\mathrm{p} K_{\mathrm{a}}$ which were estimated from DFT calculations (Figure 5D, discussed later in the computational section) and the known relationship between basicities and rate constants for the protonation of an enolate carbon site..$^{30}$ Accordingly, once $\mathbf{I}^{-}$is formed, protonation will predominantly occur at the glyoxylate/glycine site.
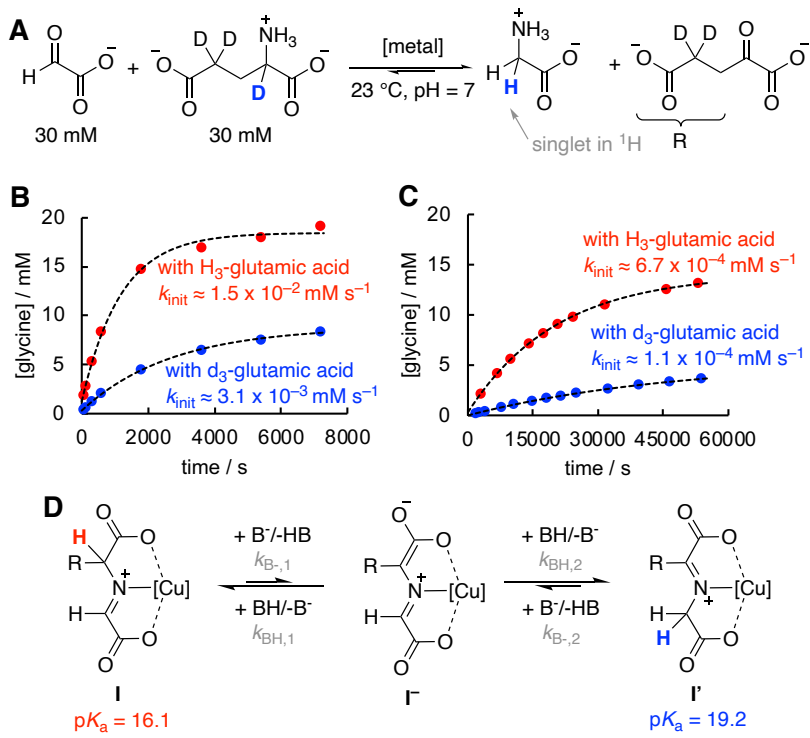

Figure 5. (A) Reaction of glyoxylate $(30 \mathrm{mM})$ with $\mathrm{d}_{3}$-glutamic acid $(30 \mathrm{mM})$. (B) Kinetics in the presence of $15 \mathrm{mM} \mathrm{Cu}^{2+}$ in $1 \mathrm{M}$ phosphate buffer and (C) $30 \mathrm{mM} \mathrm{NaVO}$ in $0.92 \mathrm{M}$ phosphate buffer at $\mathrm{pH} 7$ at $23{ }^{\circ} \mathrm{C}$. (D) Central intermediates and computed acidities $\mathrm{p} K_{\mathrm{a}}$ estimated from DFT computations (see the computational section).

Transamination Reactions of Pyruvate. Compared to the transamination reactions of glyoxylate to glycine, that of pyruvate to alanine was generally found to require longer reaction times, higher temperatures or increased catalyst concentrations (Table 2). The kinetics of the reaction of pyruvate and glutamic acid in the presence of $50 \mathrm{~mol} \%$ of $\mathrm{Cu}^{2+}$ or $\mathrm{V}^{5+}$ showed that both metals enhance the rate of transamination. In line with our initial results (Table 2), $\mathrm{Cu}^{2+}$ was found to be a more efficient catalyst than vanadate (Figure $6 \mathrm{~A} / \mathrm{B}$ ). However, when fitting the time-dependent alanine concentrations to a single-exponential, similar first-order rate constants were obtained for both the $\mathrm{V}^{5+}$ and $\mathrm{Cu}^{2+}$-catalyzed reactions. This can be explained by the slow competing decomposition of the vanadate, most likely to a $\mathrm{V}^{4+}$ species, as evidenced by the characteristic pale blue color observed after 2 weeks. ${ }^{31}$ However, since the $\mathrm{V}^{5+}$-catalyzed reaction reached significantly higher conversion to alanine at $50{ }^{\circ} \mathrm{C}$ (Table 2), we conclude that the longer reaction times at ambient temperature are problematic for the determination of reaction rates. Therefore, initial rates were used to estimate the relative effects of metal salts, which indicated that the reaction catalyzed by $\mathrm{Cu}^{2+}$ is approximately one order of magnitude faster than $\mathrm{V}^{5+}$ (Figure 6A/B). Increasing the concentration of glutamic acid had almost no effect on the rate of alanine formation with $\mathrm{Cu}^{2+}$ (Supporting Information). ${ }^{13 \mathrm{~b}}$ This suggests that the $\mathrm{Cu}^{2+}$-catalyzed transamination proceeds via an almost saturated catalyst. 

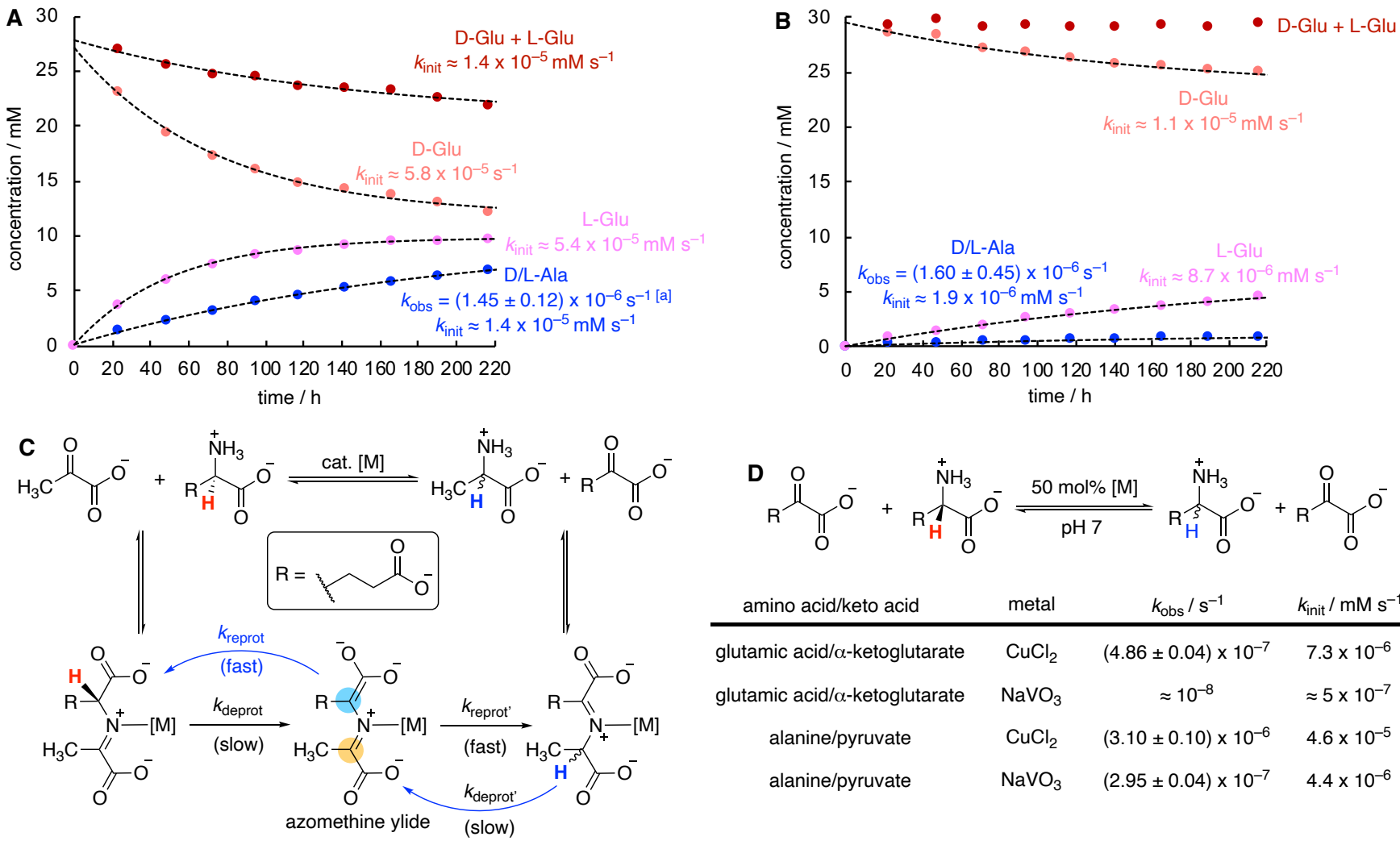

\begin{tabular}{cccc} 
amino acid/keto acid & metal & $k_{\text {obs }} / \mathrm{s}^{-1}$ & $k_{\text {init }} / \mathrm{mM} \mathrm{s}^{-1}$ \\
\hline glutamic acid/ $\alpha$-ketoglutarate & $\mathrm{CuCl}_{2}$ & $(4.86 \pm 0.04) \times 10^{-7}$ & $7.3 \times 10^{-6}$ \\
glutamic acid/ $\alpha$-ketoglutarate & $\mathrm{NaVO}_{3}$ & $\approx 10^{-8}$ & $\approx 5 \times 10^{-7}$ \\
alanine/pyruvate & $\mathrm{CuCl}_{2}$ & $(3.10 \pm 0.10) \times 10^{-6}$ & $4.6 \times 10^{-5}$ \\
alanine/pyruvate & $\mathrm{NaVO}_{3}$ & $(2.95 \pm 0.04) \times 10^{-7}$ & $4.4 \times 10^{-6}$
\end{tabular}

Figure 6. Kinetics of the reaction of pyruvate $(30 \mathrm{mM})$ with D-glutamic acid $(30 \mathrm{mM})$ in the presence of $15 \mathrm{mM} \mathrm{CuCl}_{2}(\mathrm{~A})$ or NaVO $\mathrm{Na}_{3}(\mathrm{~B})$ at $\mathrm{pH} 7$ (1 M phosphate buffer) at $23{ }^{\circ} \mathrm{C}$ (For the analogous analysis with L-glutamic acid, see the Supporting Information; dashed lines indicate the fitted kinetic curves). Concentrations were determined by manual sampling/quantitative ${ }^{1} \mathrm{H}$ NMR spectroscopy, and enantiomeric ratios were determined by chiral SFC analysis. (C) Mechanistic model for racemization/transamination illustrated starting from D-amino acids. (D) Rate constants for the racemization of L-amino acids $(30 \mathrm{mM})$ in the presence of equimolar amounts of the corresponding $\alpha$-keto acids and $15 \mathrm{mM} \mathrm{CuCl}_{2}$ or $\mathrm{NaVO}_{3}$ at $\mathrm{pH} 7\left(1 \mathrm{M}\right.$ phosphate buffer) at $23{ }^{\circ} \mathrm{C}$ as determined from manual sampling/chiral $\mathrm{SFC}$ analysis. [a] Due to the small equilibrium constant of the reaction $(\mathrm{K}=1.52),{ }^{22}$ the rate constants $k_{\text {obs }}$ shows a significant contribution of the reverse reaction with $k_{\text {forward }}=8.75 \times 10^{-7} \mathrm{~s}^{-1}$ and $k_{\text {reverse }}=5.75 \times 10^{-7} \mathrm{~s}^{-1}$.

Racemization vs Transamination. By using enantiomerically pure L- or D-glutamic acid as reactants, the concentration of all chiral species involved during the transamination process can be tracked over time (Figure 6A/B, see the Supporting Information for details). ${ }^{32}$ In this way, both the forward (transamination) and backward (racemization) reaction can be followed simultaneously. Reprotonation can either occur at the same site as deprotonation (Figure 6C, blue label), resulting in racemization, or, alternatively, on the other side, resulting in transamination (orange label). As shown in Figure 6A, we found that in the $\mathrm{Cu}^{2+}$-catalyzed reaction of pyruvate with $\mathrm{L}$ - or D-glutamic acid, racemization of glutamic acid proceeds approximately 3.9 times faster than the transamination to alanine (Figure 6A). Analogously, analysis of the initial rates in the $\mathrm{V}^{5+}$-catalyzed reaction suggested an approximately 4.6-times faster racemization compared to the transamination (Figure 6B). In the pathway in Figure $6 \mathrm{C}$, racemization might occur either due to the reprotonation of the azomethine-ylide intermediate, or due to a secondary reaction, such as the direct racemization of the amino acid by the metal or through a "transamination" with the reaction product ( $\alpha$-ketoglutarate). To differentiate between a direct racemization and these two secondary processes, we initially studied whether glutamic acid (or analogously, alanine) racemizes in the presence of $\mathrm{Cu}^{2+}$ or $\mathrm{V}^{5+}$ in the absence of keto acids. As expected, both amino acids did not show any detectable racemization. Next, we determined the rates of the racemization of a mixture of glutamic acid and $\alpha$-ketoglutarate and, analogously, of alanine and pyruvate (Figure 6D). A comparison of the initial rate of formation of L-glutamic acid from Figure $6 \mathrm{~A}\left(k_{\text {init }} \approx 5.4\right.$ $\mathrm{x} 10^{-5} \mathrm{mM} \mathrm{s}^{-1}$ ) with the rate of racemization in the presence of $\alpha$-ketoglutarate under otherwise identical reaction conditions $\left(k_{\text {init }} \approx 7.3 \times 10^{-6} \mathrm{mM} \mathrm{s}^{-1}\right)$ demonstrates that racemization predominantly occurs during re-protonation of the azomethine ylide and not as a subsequent step.

As expected from the loss of the deuterium label during the related transamination with glyoxylate (Figure 5), the reaction of pyruvate with enantiomerically pure glutamic acid yields alanine as a mixture of the D- and L-enantiomers, as chiral information is lost in the planar azomethine ylide intermediate (Figure $6 \mathrm{C}$ ). However, even if the initial transamination reaction would proceed with a slight preference for D- or L-alanine, the racemization of alanine with pyruvate with both $\mathrm{Cu}^{2+}$ or $\mathrm{V}^{5+}$ catalysts is faster than formation of alanine (Figure 6D).

How can the relative rates of racemization $\left(k_{\text {reprot }}\right)$ and transamination $\left(k_{\text {reprot' }}\right)$ of the azomethine ylide be rationalized? As discussed above, the $\mathrm{Cu}^{2+}$-catalyzed reaction seems to proceed via an almost saturated catalyst. Accordingly, in the presence of $50 \mathrm{~mol} \%$ catalyst the reaction kinetics will predominantly reflect the interconversion of the two copper-imine chelates and the reactions for their formation can be neglected. ${ }^{33}$ It has been shown that the rate constants for protonation of an enolate carbon site are linearly correlated with the basicities of the 
respective enolates. ${ }^{30}$ The higher the basicity of an enolate carbon atom, the faster its protonation by an acid, e.g., $\mathrm{H}_{3} \mathrm{O}^{+}, \mathrm{H}_{2} \mathrm{O}$, or $\mathrm{H}_{2} \mathrm{PO}_{4}^{-}$from the buffer. Therefore, the observation that glutamate racemizes faster than alanine forms, suggests that the basicity of the blue carbon atom of the azomethine ylide in Figure $6 \mathrm{C}$ is higher than that of the orange carbon atom. The validity of this interpretation will be verified in the following sections by means of DFT computations.

\section{Quantitative Analysis of the Reaction Mechanism}

Reaction Mechanism and Energy Profile. On the basis of our kinetic studies, which show the catalytic nature of the reaction, and of the established structures of metal-imine chelates, ${ }^{21,13 \mathrm{~b}}$ we proposed the reaction mechanism depicted in Scheme 1. The reaction initiates by forming small amounts of an iminium ion $\mathbf{I}-\mathbf{1}$. Exchange of $\mathrm{H}^{+}$for the transition metal results in a metal-imine complex I-2. Deprotonation of $\mathbf{I}-\mathbf{2}$ yields the fully conjugated azomethine ylide I-3 which upon re-protonation forms either the original imine adduct $\mathbf{I}-\mathbf{2}$ or the isomeric I-2'. Hydrolysis of I-2' finally liberates the reaction products. In the presence of catalytic amounts of metal, the whole sequence is reversible and will result in concentrations of amino and keto acids depending on the relative energies of reactants and products. ${ }^{22,23}$ By forming the metal-imine chelates I-2, metal ions can influence the rate of the transamination sequence through two predominant mechanisms, which are not mutually exclusive. Either they can increase the concentration of the reactive imine intermediate, by enforcing a higher binding constant, or they can increase the acidity of the $\mathrm{CH}$ moiety in $\mathbf{I - 2}$ and therefore the rate of deprotonation to I-3. Alternatively, the transamination reaction can also proceed via a significantly slower metal-free pathway through direct deprotonation of the iminium species I-1 to azomethine ylide $\mathbf{I}-\mathbf{4}$.

Scheme 1. Proposed Reaction Mechanism for Catalytic Transamination

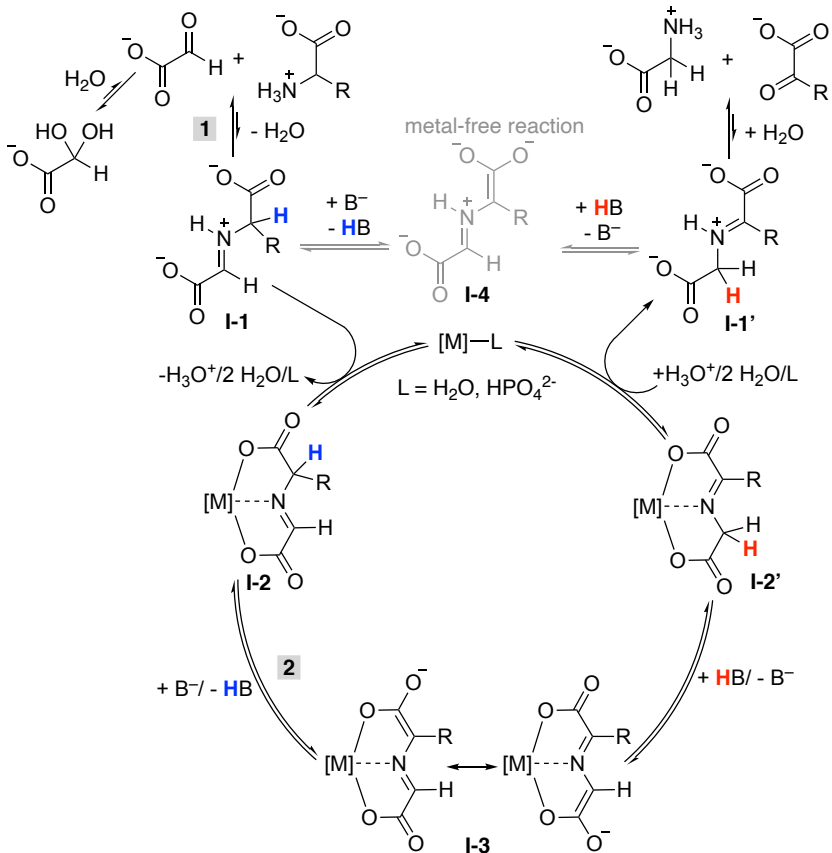

To get further insights into the reaction mechanism, we performed DFT calculations of the $\mathrm{V}^{5+}$-catalyzed reaction pathway using the MN15/Def2-TZVP level of theory considering solvation by the SMD solvation model for water as included in the Gaussian package. ${ }^{34}$ The MN15 functional was chosen because it was previously shown to be broadly applicable for various bonding situations, including transition-metals. ${ }^{35}$ The full Gibbs energy profiles for the uncatalyzed and vanadate-catalyzed reaction of glyoxylate and pyruvate with glutamic acid are depicted in Figure 7. The key steps of the reaction are discussed below based on both experimental results and our DFT computations.

Step 1 - Imine Formation. The general mechanism of imine formation starting from amino and keto acids has previously been studied both experimentally and computationally. ${ }^{36}$ The observation of a significant deuterium isotope effect for the $\mathrm{Cu}^{2+}$ - and $\mathrm{V}^{5+}$-catalyzed reactions of glyoxylate with glutamic acid (Figure 5) points to rate-determining deprotonation. We therefore consider imine formation to be comparably fast and focused our analysis of this step exclusively on the thermochemistry. However, few experimental equilibrium constants for the reaction of amino acids with $\alpha$-keto acids to yield imine/iminium ions I-1 in aqueous solutions are known due to the practical challenges associated with their determination. ${ }^{37,38}$ To still get insight into the thermochemistry for the systems relevant to our study, we therefore used DFT computations (Table 4). Our computations (Table 4, Figure 7) suggest that the formation of the iminium ions I-1 is weakly exergonic with glycine or alanine, in line with available experimental values, ${ }^{37}$ and endergonic with glutamic acid. The more unfavored thermochemistry in the case of glutamic acid found in the computations can be attributed to the disruption of the intramolecular hydrogen bond between the terminal carboxy and the amino group in the reactant, which cannot form in the iminium ion $\mathbf{I - 1}$. This initial endergonic step can be compensated to a certain degree by the formation of metal chelates. For example, complexation with $\mathrm{V}^{5+}$ is energetically slightly favored according to our computations (Figure 7).

Table 4. Gibbs Free Energy $\left(\mathrm{kJ} \mathrm{mol}^{-1}\right)$ for Iminium Formation $\left(\mathrm{SMD}\left(\mathrm{H}_{2} \mathrm{O}\right) / \mathrm{MN15} / \mathrm{Def} 2-\mathrm{TZVP}\right){ }^{\mathrm{a}}$

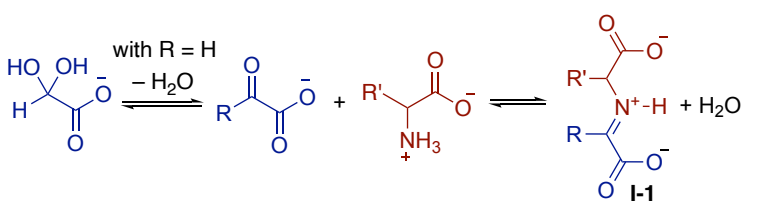

\begin{tabular}{cccc}
\hline & \multicolumn{3}{c}{ amino acid } \\
\cline { 2 - 4 } Keto acid & glycine & alanine & glutamic acid \\
\hline glyoxylate & -1.6 & -1.0 & +9.9 \\
pyruvate & -12.9 & -9.1 & +3.9 \\
a-ketoglutarate & -13.7 & -10.8 & +10.3 \\
\hline
\end{tabular}

a in aqueous solution, the predominant form of glyoxylate is the hydrate with $\Delta \mathrm{G}^{0}=-6.7 \mathrm{~kJ} \mathrm{~mol}^{-1} .^{39}$

A more complex situation arises in the presence of other metal ions due to the large number of possible species. Detailed investigations on the $\mathrm{pH}$-dependent species distribution in the reactions of pyruvate and glyoxylate with different amino acids in the presence of $\mathrm{Ni}^{2+}$ and $\mathrm{Zn}^{2+}$ ions have been performed by Leussing. ${ }^{21 f^{\prime}}$ In the $\mathrm{Ni}^{2+}$-glyoxylate-alanine system, the predominant species at neutral $\mathrm{pH}$ are complexes with the imine $(1: 1$ and 1:2 complexes are possible). Stability constants for the 
keto/amino acid systems with metals were only reported with $\mathrm{Ni}^{2+}$ and $\mathrm{Zn}^{2+}$. However, Leussing found that the stability constants with the imine ligand are of similar magnitude than those with iminodiacetic acid, which are reported for many metal ions (Table 5). ${ }^{21 f^{\prime}}$ The highest stability constants were observed with $\mathrm{Cu}^{2+}$, followed by $\mathrm{Ni}^{2+}$ and $\mathrm{Co}^{2+}$, a ranking agreeing with the reactivity order of the metals identified in our kinetic studies (Figure 4B).

Table 5. Stability Constants $\lg K$ for Complexes of Iminodiacetic acid with Different Divalent Metals at $20^{\circ} \mathrm{C}^{40}$

$\mathrm{M}$

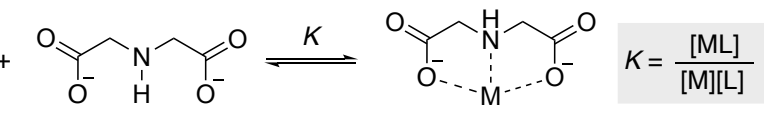

\begin{tabular}{cccccc}
\hline Metal & $\mathrm{H}^{+}$ & $\mathrm{Fe}^{2+}$ & $\mathrm{Co}^{2+}$ & $\mathrm{Ni}^{2+}$ & $\mathrm{Cu}^{2+}$ \\
\hline $\lg \beta$ & 9.45 & 5.8 & 6.97 & 8.19 & 10.6 \\
\hline
\end{tabular}

Step 2 - Deprotonation. Deprotonation of the iminium species I-1 or metal-imine chelate I-2, to yield I-4 or I-3, respectively, can occur by either $\mathrm{HPO}_{4}{ }^{2-}$ ions from the buffer by means of general base catalysis or hydroxide ions in the solvent. ${ }^{12 \mathrm{e}, 28 \mathrm{~b}, 28 \mathrm{~d}, 30,41,42}$ Since the concentrations of hydroxide and $\mathrm{HPO}_{4}{ }^{2-}$ stay almost constant during the reaction, pseudo-first order kinetics result for the deprotonation (Figures 2-6). However, the vanadate ions in the pathways in Figure 7 do not only affect the reaction by the energetics of chelate formation. Comparing the relative Gibbs energies of $\mathbf{I - 2} / \mathbf{I}-\mathbf{3}\left(\Delta \mathrm{G}^{0}=+27.6 \mathrm{~kJ}\right.$ $\mathrm{mol}^{-1}$ for glyoxylate/glutamate) and $\mathbf{I - 1} / \mathbf{I}-4\left(\Delta \mathrm{G}^{0}=+49.3 \mathrm{~kJ}\right.$ $\mathrm{mol}^{-1}$ for glyoxylate/glutamate) in their deprotonation reaction with $\mathrm{HPO}_{4}{ }^{2-}$ indicates that the $\mathrm{CH}$ group is more acidic in the vanadate complex $\mathbf{I}-\mathbf{2}$ than in the iminium ion $\mathbf{I}-\mathbf{1}$. In line with the higher acidity of $\mathbf{I}-\mathbf{2}$ compared to $\mathbf{I}-\mathbf{1}$, computations found a lower activation barrier for the deprotonation of $\mathbf{I}-\mathbf{2}$ than for $\mathbf{I}-$ 1 by $\mathrm{HPO}_{4}{ }^{2-}$. Accordingly, the role of vanadate as catalyst can be assigned to reducing the barrier for deprotonation by increasing the acidity of $\mathbf{I - 2}$ compared to $\mathbf{I}-\mathbf{1}$. The relationship between the acidity of the substrate and the barrier of deprotonation was found to hold for all studied substrates as shown in the Brønsted-type correlation in Figure S21. Generally, the same trends as found with $\mathrm{HPO}_{4}{ }^{2-}$ were observed when the transition states were studied with hydroxide acting as base (solvated with an explicit water molecule; see the Supporting Information). Due to the higher basicity of hydroxide compared to $\mathrm{HPO}_{4}{ }^{2-}$, the deprotonation reaction proceeds via lower activation barriers and is more exergonic. However, the concentration of hydroxide at $\mathrm{pH} 7$ is almost seven orders of magnitude lower than that of $\mathrm{HPO}_{4}{ }^{2-}$. Accordingly, both bases can be expected to be involved in the reaction. For the vanadate-catalyzed reaction, the mixed vanadate/phosphate anhydride might act as base via either the vanadate or phosphate sites. However, computations indicate a slightly higher activation barrier for deprotonation of I-1 by the anhydride than by $\mathrm{HPO}_{4}{ }^{2-}$, rendering this option less likely (see Supporting Information S146 for details).

In the case of the reaction between pyruvate and glutamic acid, racemization studies (Figure 6A/B) in the presence of both $\mathrm{Cu}^{2+}$ and vanadate suggested that re-protonation is rate-determining. For the vanadate-catalyzed reaction, the experimental ratio of the rates of racemization and transamination of 4.6 (Figure 6B) translates to a difference in the activation barriers $\Delta \Delta \mathrm{G}^{\#}$
$=3.7 \mathrm{~kJ} \mathrm{~mol}^{-1}$. In line with those experiments, the DFT computations in Figure 7B correctly predict that the activation barrier for protonating the pyruvate site of $\mathbf{I}-\mathbf{3}$ via TS $2_{\mathrm{V}}$ is $3.6 \mathrm{~kJ} \mathrm{~mol}^{-1}$ higher than re-protonation at the glutamate site via $\mathrm{TS} 1_{\mathrm{V}}$, the latter additionally being less basic. However, our computations showed higher errors in reproducing the thermochemistry of the transamination reactions. We attribute this to a systematic error due to the insufficient description of aqueous solvation by the implicit solvation model used in our studies.

Acidities of Imines and Roles of Different Metals. The observation that the de- or re-protonation step is rate-determining for the overall transamination reaction suggests that the imine $\mathrm{C}-\mathrm{H}$ acidity $\left(\mathrm{p} K_{\mathrm{a}}\right)$ can predict, in part, the reaction rate and whether de- or re-protonation is rate-determining.

The relationship between the rate constants and $\mathrm{p} K_{\mathrm{a}}$ for the deprotonation of amino acids and iminium ions has been extensively studied by Richard and coworkers by measuring the rate constants of deuterium exchange of the amino acids' $\mathrm{CH}$ protons. ${ }^{28}$ To connect the systems investigated in the present study to Richard's experimental acidities, we again used DFT computations. As discussed in detail in the Supporting Information, a set of 12 imines and iminium ions for which experimental $\mathrm{p} K_{\mathrm{a}}$ values are known were calculated by DFT to give the acidities $\mathrm{p} K_{\mathrm{a}, \mathrm{DFT}}$. The linear correlation of experimental $\mathrm{p} K_{\mathrm{a}}$ with computed $\mathrm{p} K_{\mathrm{a}, \mathrm{DFT}}$ values (Figure $\mathrm{S} 17$ ) can thus be used to link computed acidities to known experimental values, reducing the absolute error of the DFT computations. Figure 8 shows the predicted acidities of imines and iminium ions $\left(\mathrm{p} K_{\mathrm{a}, \text { corrDFT }}\right)$ resulting from the combination of glyoxylate, pyruvate and $\alpha$-ketoglutarate with glycine, alanine and glutamic acid, as well as those of the metal-imine complexes with $\mathrm{Cu}^{2+}$ and $\mathrm{V}^{5+}$ ions. Additionally, the imine chelate derived from glyoxylate and glycine was studied with $\mathrm{Co}^{2+}$ and $\mathrm{Ni}^{2+}$ ions. The computed acidities of the $\mathrm{CH}$-protons of the iminium ions range from 13.9 to 20.6, thus being within the range of experimental values reported by Richard. ${ }^{28 g}$ In line with experimental findings, our computations predict that iminium ions are 6 to $10 \mathrm{p} K_{\mathrm{a}}$ units more acidic than the respective imines. ${ }^{28 g}$ Analogously, the imine-metal complexes are more acidic than the imine alone, though to different extents.

Generally, we found that imine species derived from glyoxylate have a higher acidity than those derived from pyruvate and $\alpha$-ketoglutarate. However, the effect of the amino acid partner on the acidity is not as systematic. For the imines derived from pyruvate and $\alpha$-ketoglutarate, the highest acidities are observed with glycine as the amino acid fragment. In line with the computed Gibbs energy profile (Figure 7), the comparison of the imines' $\mathrm{p} K_{\mathrm{a}}$ values suggests that the reaction of glyoxylate with alanine or glutamate proceeds via rate-determining deprotonation, while the reaction of pyruvate with glutamic acid features rate-determining re-protonation (vide supra).

Moreover, the acidities in Figure 8 now allow us to assess the predominant way by which different metal ions catalyze transamination. Coordination of $\mathrm{Cu}^{2+}$ generally results in an identical or even slightly weaker activation of the $\mathrm{CH}$ acidity compared to the iminium ions, where $\mathrm{H}^{+}$is coordinated. This observation is in line with Toney's finding that $\mathrm{Al}^{3+}$ is a weaker activator of imines compared to $\mathrm{H}^{+}$. ${ }^{12 \mathrm{~h}} \mathrm{Like} \mathrm{Cu}^{2+}$, coordination of $\mathrm{Co}^{2+}$ does not significantly increase the acidity of the imines' $\mathrm{CH}$ proton, as shown for the glycine/glyoxylate pair. 


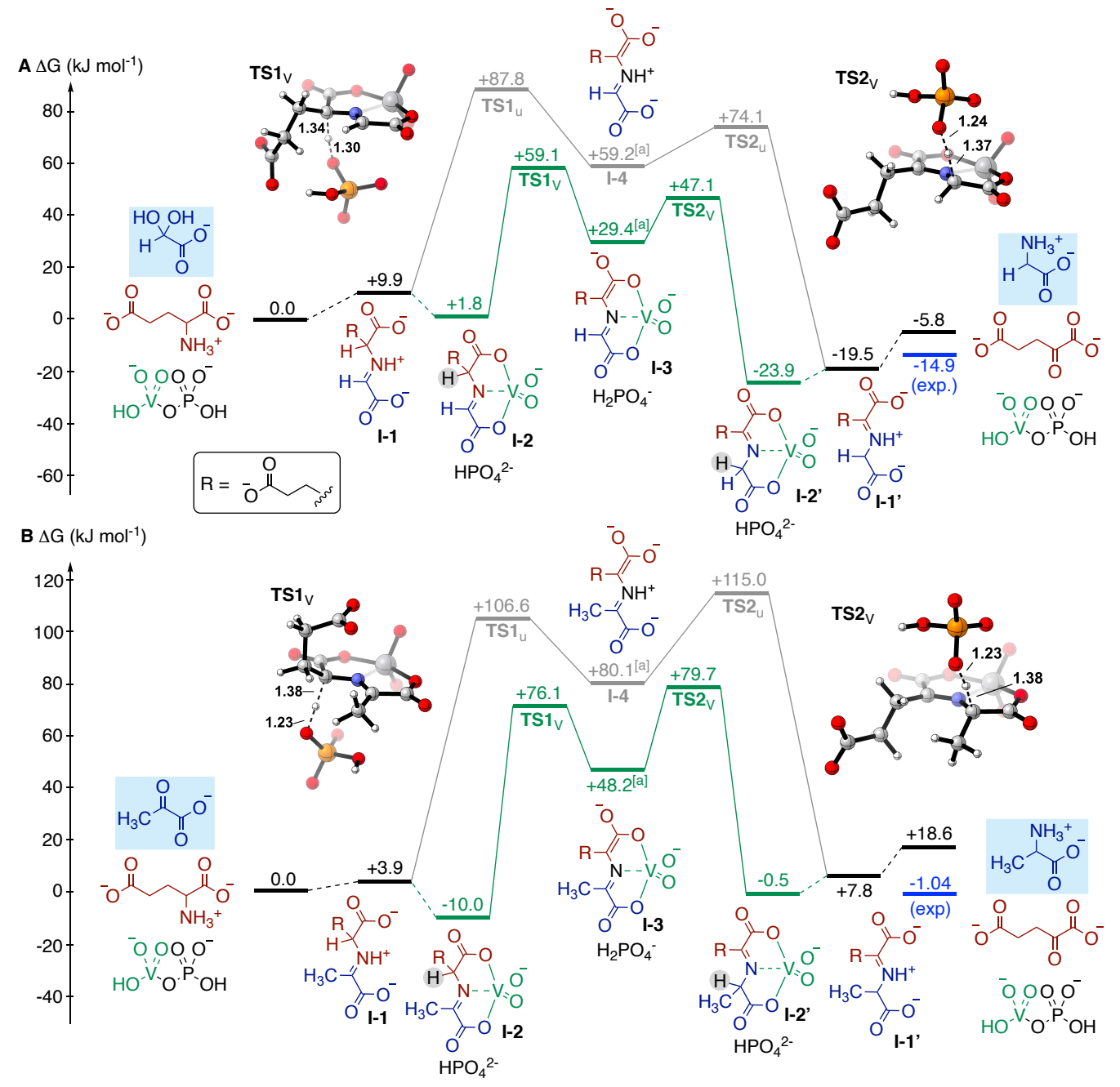

Figure 7. Gibbs energy profile for the uncatalyzed (grey) and vanadate (green) catalyzed reaction of (A) glyoxylate with glutamic acid and (B) pyruvate with glutamic acid calculated at the $\mathrm{SMD}\left(\mathrm{H}_{2} \mathrm{O}\right) / \mathrm{MN} 15 / \mathrm{Def} 2-\mathrm{TZVP}$ level of theory using $\mathrm{HPO}_{4}{ }^{2-}$ as base for the de-/re-protonation step. Inserts: Structures of the located transition states for the deprotonation reaction of the vanadate chelates. [a] Gibbs energies calculated based on the difference of $\mathrm{p} K_{\mathrm{a}}$ values (see Supporting Information).

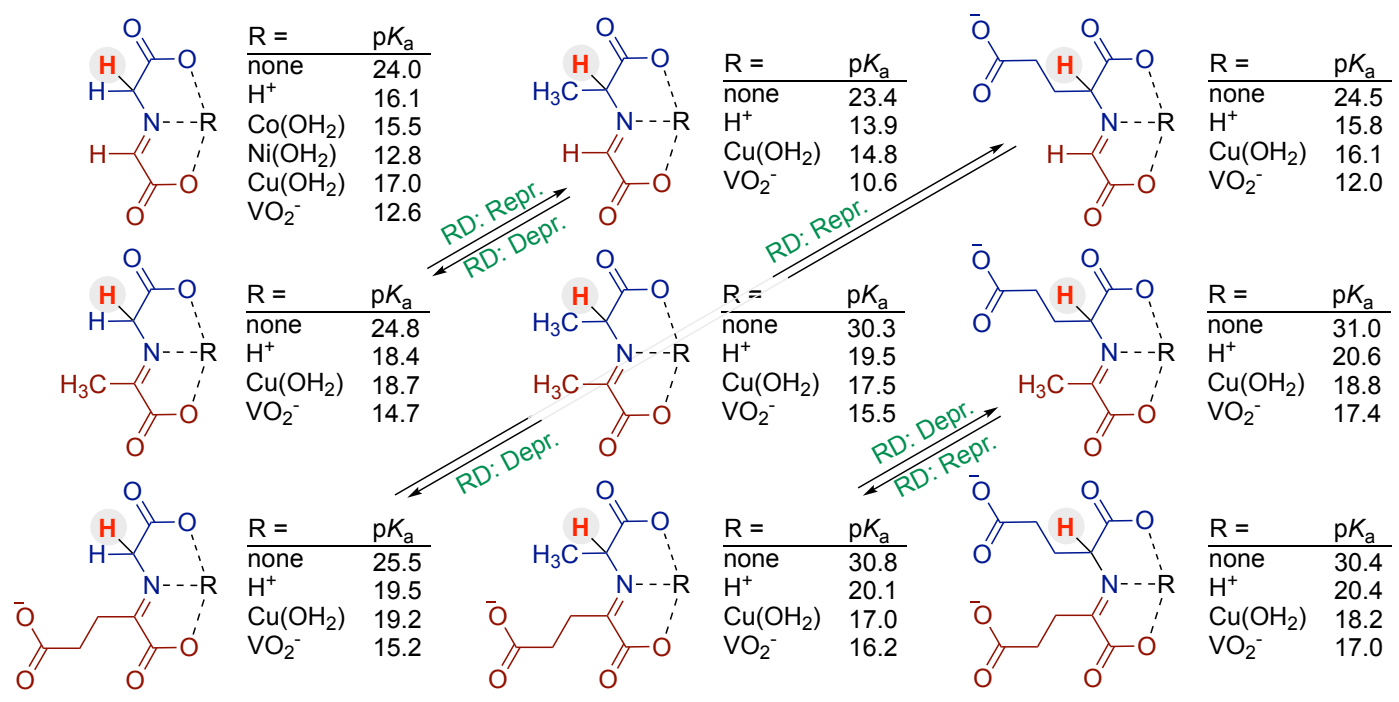

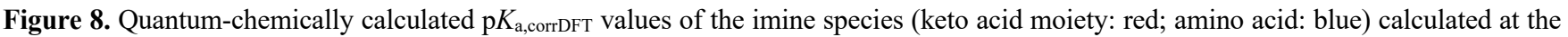
$\mathrm{SMD}\left(\mathrm{H}_{2} \mathrm{O}\right) / \mathrm{MN} 15 /$ Def2-TZVP level of theory, corrected with the experimental $\mathrm{p} K_{\mathrm{a}}$ values $\left(\mathrm{H}_{2} \mathrm{O}, 25{ }^{\circ} \mathrm{C}\right)$ from ref. $28 \mathrm{~g}$ as outlined in the Supporting Information. Arrows indicate the nature of the rate determining step (RD) for a specific direction of the reaction (Depr.: deprotonation; Repr.: Reprotonation). 
Accordingly, the catalytic activity of $\mathrm{Co}^{2+}$ and $\mathrm{Cu}^{2+}$ can be predominantly assigned to the high stability of the metal-imine complexes and not to activation of the substrate.

With $\mathrm{Ni}^{2+}$ and $\mathrm{V}^{5+}$, however, the acidity of the imine ligand is generally enhanced compared to the protonated imines. Formation of the $\mathrm{V}^{5+}$-imine complexes is only slightly exergonic and accordingly the catalytic activity of $\mathrm{V}^{5+}$ in transamination reactions can be mostly attributed to the increase of acidity of the substrates. With $\mathrm{Ni}^{2+}$, however, the stability constants determined by Leussing for the pyruvate $/ \mathrm{Ni}^{2+}$ system suggest that also high amounts of the imine- $\mathrm{Ni}^{2+}$ chelates are formed. ${ }^{21 \mathrm{~b}-\mathrm{e}}$ Accordingly, the catalytic activity of $\mathrm{Ni}^{2+}$ can be attributed both to strong chelation and to activation of the $\mathrm{CH}$ acidity.

\section{Conclusion}

Transamination reactions have been known for decades to occur in the absence of enzymes. While non-enzymatic transamination involving PLP has been studied with and without additional metals, it was not known to what extent metals alone can act as catalysts under biological conditions, or even whether they can display catalytic turnover. In this work, we have shown that $\mathrm{Co}^{2+}, \mathrm{Ni}^{2+}, \mathrm{Cu}^{2+}$ and $\mathrm{V}^{5+}$ ions can, not just promote, but efficiently catalyze transamination reactions even without PLP (up to 2700-fold acceleration in the case of $50 \mathrm{~mol} \% \mathrm{Cu}^{2+}$ ). A combination of kinetic and mechanistic experiments together with DFT calculations provided insights into the key steps of the reaction and a rationale for the two major ways in which metals can catalyze transamination reactions.

$\mathrm{Co}^{2+}$ and $\mathrm{Cu}^{2+}$ primarily increase the rate of transamination by increasing the available concentration of the reactive metalimine chelate intermediates. $\mathrm{V}^{5+}$ predominantly speeds the rate by increasing the acidity of the imine chelate's $\mathrm{CH}$-protons, which in turn increases the rate constant for the key deprotonation step. $\mathrm{Ni}^{2+}$ works by both of these mechanisms to a certain extent. In metal-catalyzed transamination reactions, both de- or re-protonation can be the rate-determining step of the overall sequence, depending on the reaction partner, as supported by racemization experiments. Acidity constants of the iminium ions or metal-imine chelates can be used to predict both the nature of the rate-determining step, as well as the extent of activation of different combination of amino/keto acids and catalysts.

When using enantiopure glutamic acid as reactant, chirality is not transferred to the product (Figure 6). This highlights one of the key functions of enzymes in transamination reactions that cannot be achieved in non-enzymatic metal-catalyzed reactions in a straightforward way: the control of stereochemistry. Nonetheless, the mild conditions under which the metal ion-catalyzed reaction operates and the specific mechanistic insight gained in the current study raises the possibility that biological transamination might have undergone an evolutionary progression from metal catalysis to PLP catalysis to PLP/transaminase catalysis without a fundamental change to the mechanism. This makes transamination a rare metabolic process in which the mechanism is well understood across metal ion, co-factor, and co-factor/enzyme catalysis. Obtaining mechanistic insight into how both biological and non-biological catalysts enable metabolic processes under biological conditions should continue to illuminate how they emerged from the earliest stages.

\section{ASSOCIATED CONTENT}

\section{Supporting Information}

The Supporting Information is available free of charge on the ACS Publications website.

Full experimental details, representative NMR spectra of product studies, raw data and fitted curves for the individual kinetic experiments, procedure of quantum-chemical calculations and xyz coordinates of all optimized structures (PDF).

\section{AUTHOR INFORMATION}

\section{Corresponding Author}

*moran@unistra.fr

\section{Author Contributions}

\$ R.J.M and H.K contributed equally.

\section{ACKNOWLEDGMENT}

This project has received funding from the European Research Council (ERC) under the European Union's Horizon 2020 research and innovation programme (grant agreement $n^{\circ} 101001752$ ) and for S.A.R with the Marie Skłodowska-Curie grant agreement No 813873, ProtoMet "Protometabolic pathways: exploring the chemical roots of systems biology". The work was also supported by the Interdisciplinary Thematic Institute ITI-CSC via the IdEx Unistra (ANR-10-IDEX-0002) within the program Investissement d'Avenir. J.M. thanks the VW Foundation (no. 96_742) for generous support. R.J.M thanks the Deutsche Forschungsgemeinschaft (DFG, German Research Foundation) for a fellowship (MA 9687/1-1). Computations were performed at the High Performance Computing Center of the University of Strasbourg. Part of the computing resources were funded by the Equipex Equip@Meso project (Programme Investissements d'Avenir) and the CPER Alsacalcul/Big Data. Dr. Nicolas Zeidan, Dr. Paweł Dydio (Strasbourg, France) and Prof. Claude Y. Legault (Sherbrooke, Canada) are acknowledged for helpful discussions.

\section{REFERENCES}

(1) Krebs, H. A. The Effect of Inorganic Salts on the Ketone Decomposition of Oxaloacetic Acid. Biochem. J. 1942, 36, 303-305.

(2) Westheimer, F. W. The mechanisms of some metal-ion-promoted reactions. Trans. N. Y. Acad. Sci. 1955, 18, 15-21.

(3) Kluger, R. Thiamin Diphosphate: A Mechanistic Update on Enzymic and Nonenzymic Catalysis of Decarboxylation. Chem. Rev. 1987, 87, 863-876.

(4) (a) Ralser, M. An Appeal to Magic? The Discovery of a NonEnzymatic Metabolism and Its Role in the Origins of Life. Biochem. J. 2018, 475, 2577-2592. (b) Muchowska, K. B.; Varma, S. J.; Moran, J. Nonenzymatic Metabolic Reactions and Life's Origins. Chem. Rev. 2020, 120, 7708-7744.

(5) (a) Muchowska, K. B.; Varma, S. J.; Chevallot-Beroux, E.; Lethuillier-Karl, L.; Li, G.; Moran, J. Metals promote sequences of the reverse Krebs cycle. Nat. Ecol. Evol. 2017, 1, 1716-1721. (b) Muchowska, K. B.; Varma, S. J.; Moran, J. Synthesis and breakdown of universal metabolic precursors promoted by iron. Nature 2019, 569, 104-107.

(6) (a) Varma, S. J.; Muchowska, K. B.; Chatelain, P.; Moran, J. Native iron reduces $\mathrm{CO}_{2}$ to intermediates and end-products of the acetyl CoA pathway. Nat. Ecol. Evol. 2018, 2, 1019-1024 (b) Preiner, M.; Igarashi, K.; Muchowska, K. B.; Yu, M.; Varma, S. J.; Kleinermanns, K.; Nobu, M. K.; Kamagata, Y.; Tüysüz, H.; Moran, J.; Martin, W. F. A Hydrogen-Dependent Geochemical Analogue of Primordial Carbon and Energy Metabolism. Nat. Ecol. Evol. 2020, 4, 534-542.

(7) (a) Keller, M. A.; Turchyn, A. V.; Ralser, M. Non-enzymatic Glycolysis and Pentose Phosphate Pathway-like Reactions in a Plausible Archean Ocean. Mol. Syst. Biol. 2014, 10, 725. (b) Keller, M. A.; Zylstra, A.; Castro, C.; Turchyn, A. V.; Griffin, J. L.; Ralser, M. 
Conditional Iron and PH-Dependent Activity of a Non-Enzymatic Glycolysis and Pentose Phosphate Pathway. Sci. Adv. 2016, 2, e1501235.

(8) Messner, C. B.; Driscoll, P. C.; Piedrafita, G.; Volder, M. F. L. D.; Ralser, M. Nonenzymatic Gluconeogenesis-like Formation of Fructose 1,6-Bisphosphate in Ice. Proc. Natl. Acad. Sci. 2017, 114, 74037407.

(9) (a) Wächtershäuser, G. Before enzymes and templates: theory of surface metabolism. Microbiol. Rev. 1988, 52, 452-484. (b) Martin, W., Russell, M. J. On the origin of biochemistry at an alkaline hydrothermal vent. Philos. Trans. R. Soc. B Biol. Sci. 2007, 362, 1887-1925. (c) Copley, S. D., Smith, E., Morowitz, H. J. The origin of the RNA world: co-evolution of genes and metabolism. Bioorg. Chem. 2007, 35, 430-443.

(10) (a) Biochemistry - The Chemical Reactions of Living Cells, 2nd ed. Vol. 2. Metzler, D. E.; Academic Press, San Diego. (b) McMurry, J. E.; Begley, T. P.; The Organic Chemistry of Biological Pathways, 2nd ed.; Roberts and Company: Greenwood Village, CO, 2016.

(11) Eliot, A. C.; Kirsch, J. F. Pyridoxal Phosphate Enzymes: Mechanistic, Structural, and Evolutionary Considerations. Annu. Rev. Biochem. 2004, 73, 383-415.

(12) (a) Metzler, D. E.; Olivard, J.; Snell, E. E. Transamination of Pyridoxamine and Amino Acids with Glyoxylic Acid. J. Am. Chem. Soc. 1954, 76, 644-648. (b) Longenecker, J. B.; Metzler, E. E. The Comparative Activities of Metal Ions in Promoting Pyridoxal-catalyzed Reactions of Amino Acids. J. Am. Chem. Soc. 1957, 79, 142-145. (c) Matsuo, Y. Pyridoxal Catalysis of Non-enzymatic Transamination in Ethanol Solution. J. Am. Chem. Soc. 1957, 79, 2016-2019. (d) Eichhorn, G. L.; Dawes, J. W. The Metal Complexes of Vitamine $\mathrm{B}_{6}$ and Schiff's Base Derivatives. J. Am. Chem. Soc. 1954, 76, 5663-5667. (e) Banks, B. E. C.; Diamantis, A. A.; Vernon, C. A. Transamination. Part II. The Non-enzymic Reaction between Pyridoxamine and Pyruvic Acid and between Pyridoxal and Alanine. J. Chem. Soc. 1961, 42354247. (f) Auld, D. S.; Bruice, T. C. Catalytic Reactions Involving Azomethines. IX. General Base Catalysis of the Transamination of 3-Hydroxypyridine-4-aldehyde by Alanine. J. Am. Chem. Soc. 1967, 89, 2098-2106. (g) Meisch, H.-U.; Hoffmann, H.; Reinle, W. Vanadium Catalysis in the Nonenzymatic Transamination of $\delta$-Aminolevulinic Acid. Z. Naturforsch. C 1978, 33, 623-628. (h) Zabinski, R. F.; Toney, M. D. Metal Ion Inhibition of Nonenzymatic Pyridoxal Phosphate Catalyzed Decarboxylation and Transamination. J. Am. Chem. Soc. 2001, 123, 193-198. See references cited therein for a critical discussion.

(13) (a) Metzler, D. E.; Snell, E. E. Some Transamination Reactions Involving Vitamine $\mathrm{B}_{6} . J$. Am. Chem. Soc. 1952, 74, 979-983. (b) Mix, H. Nichtenzymatische Transaminierung zwischen a-Aminosäuren und a-Ketosäuren in Gegenwart von Metallionen. Hoppe Seylers Z. Physiol. Chem. 1959, 314, 1-12. (c) Mix, H.; Wilcke, F. W. Nichtenzymatische Reaktionen zwischen a-Aminosäuren und a-Ketosäuren, II. Hoppe Seylers Z. Physiol. Chem. 1960, 318, 148-158. (d) Cabello, J.; Basilio, C.; Prajoux, V.; Plaza, M. Non-Enzymatic Transamination between Ornithine and Glyoxylate. Arch. Biochem. Biophys. 1963, 100, 512-515. (e) Doctor, V. M.; Oró, J. Mechanism of Non-Enzymatic Transamination Reaction between Histidine and a-Oxoglutaric Acid. Biochem. J. 1969, 112, 691-697. (f) Stubbs, R. T.; Yafav, M.; Krishnamurthy, R.; Springsteen, G. A plausible metal-free ancestral analogue of the Krebs cycle composed entirely of $\alpha$-ketoacids. Nat. Chem. 2020, 12, 1016-1022.

(14) (a) Herbst, R. M.; Engel, L. L. A Reaction Between $\alpha$-Ketonic acids and $\alpha$-Amino acids. J. Biol. Chem. 1934, 107, 505-512. (b) Herbst, R. M. The Reaction between $\alpha$-Ketonic Acids and $\alpha$-Amino Acids, J. Am. Chem. Soc. 1936, 58, 2239-2243. (c) Nakada, H. I.; Weinhouse, S. Non-Enzymatic Transamination with Glyoxylic Acid and Various Amino Acids. J. Biol. Chem. 1953, 204, 831-836.

(15) For a review, see: Xie, Y.; Pan, H.; Liu, M.; Xiao, X.; Shi, Y. Progress in asymmetric biomimetic transamination of carbonyl compounds. Chem. Soc. Rev. 2015, 44, 1740-1748.

(16) (a) Liu, L; Zhou, W.; Chruma, J.; Breslow, R. Transamination Reactions with Multiple Turnovers Catalyzed by Hydrophobic Pyridoxamine Cofactors in the Presence of Polyethylenimine Polymers. $J$. Am. Chem. Soc. 2004, 126, 8136-8137. (b) Wei, S.; Wang, J.; Venhuizen, S.; Skouta, R.; Breslow, R. Dendrimers in solution can have their remote catalytic groups folded back into the core: Enantioselective transaminations by dendritic enzyme mimics-II. Bioorg. Med. Chem. Lett. 2009, 19, 5543-5546. (c) Xiao, X.; Xie, Y.; Su, C.; Shi, Y. Organocatalytic Asymmetric Biomimetic Transamination: From $\alpha$ Keto Esters to Optically Active $\alpha$-Amino Acid Derivatives. $J$. Am. Chem. Soc. 2011, 133, 12914-12917. (d) Shi, L.; Tao, C.; Yang, Q.; Liu, Y. E.; Chen, J.; Chen, J.; Tian, J.; Liu, F.; Li, B.; Du, Y.; Zhao, B. Chiral Pyridoxal-Catalyzed Asymmetric Biomimetic Transamination of $\alpha$-Keto Acids. Org. Lett. 2015, 17, 5784-5787. (e) Liu, Y. E.; Lu, Z.; Li, B.; Tian, J.; Liu, F.; Zhao, J.; Hou, C.; Li, Y.; Niu, L.; Zhao, B. Enzyme-Inspired Axially Chiral Pyridoxamines Armed with a Cooperative Lateral Amine Chain for Enantioselective Biomimetic Transamination. J. Am. Chem. Soc. 2016, 138, 10730-10733. (f) Chen, J.; Gong, X.; Li, J.; Li, Y.; Ma, J.; Hou, C.; Zhao, G.; Yuan, W.; Zhao, B. Carbonyl catalysis enables a biomimetic asymmetric Mannich reaction. Science 2018, 360, 1438-1442.

(17) (a) Kuzuhara, H.; Komatsu, T.; Emoto, S. Synthesis of Chiral Pyridoxamine Analog and Nonenzymatic Stereoselective Transamination. Tetrahedron Lett. 1978, 38, 3563-3566. (b) Kukuchi, J.-I.; Zhang, Z.-Y.; Murakami, Y. Enantioselective Catalysis by a Supramolecular Bilayer Membrane as an Artificial Aminotransferase. Stereochemical Role of an L-Lysine Residue and L-Phenylalanine at the Reaction Site. J. Am. Chem. Soc. 1995, 117, 5383-5384.

(18) Tan, X.; Liu, C.-F. Investigating Glyoxylate-Mediated Transamination Using Dipeptide Arrays and Proteomic Peptide Mixtures. Bioconjugate Chem. 2018, 29, 3285-3292.

(19) Garrett, R. G. Natural Sources of Metals to the Environment. Hum. Ecol Risk Assess. Int. J. 2000, 6, 945-963.

(20) Conley, M.; Mojica, M.; Mohammed, F.; Chen, K.; Napoline, J. W.; Pollet, P.; Wang, J.; Krishnamurthy, R.; Liotta, C. L. Reaction of glycine with glyoxylate: Competing transaminations, aldol reactions, and decarboxylations. J. Phys. Org. Chem. 2017, 30, e3709.

(21) (a) Witkop, B.; Beiler, T. W. Studies on Schiff Bases in Connection with the Mechanism of Transamination. J. Am. Chem. Soc. 1954, 76, 5589-5597. (b) Leussing, D. L. The Determination of the Stabilities of Schiff Base Complexes Involving Dissociated Schiff Bases. J. Am. Chem. Soc. 1963, 85, 231-232. (c) Leussing, D. L.; Stanfield, C. K. A Nuclear Magnetic Resonance Study of Aqueous Pyruvate-Glycinate-Zinc(II) and Related Systems. J. Am. Chem. Soc. 1964, 86, 2805-2810; (d) Nakahara, A.; Yamamoto, H.; Matsumoto, H. The Stability of Fused Rings in Metal Chelates. II. Copper(II) Complexes of Schiff Bases Derived from Pyruvic Acid and Amino Acids or Diamines. Bull. Chem. Soc. Jpn. 1964, 37, 1137-1142; (e) Leussing, D. L. A Numerical Study of the Nickel-Pyruvate-Glycinate System Using a High Speed Computer. Talanta 1964, 11, 189-201. (f) Leussing, D. L.; Shultz, D. C. Metal Ion Catalysis in Transamination. II. Pyruvate-Glycinate Equilibrium Systems with Some Divalent Metal Ions. J. Am. Chem. Soc. 1964, 86, 4846-4850. (g) Nakao, Y.; Sakurai, K.-I.; Nakahara, A. The Copper(II) Complex of Schiff Base Derived from Glyoxylic Acid and $\alpha$-Alanine. Bull. Chem. Soc. Jpn. 1965, 38, 687688. (h) Leussing, D. L.; Hanna, E. M. Metal Ion Catalysis in Transamination. III. Nickel(II) and Zinc(II) Mixed Complexes Involving Pyruvate and Various Substituted Aliphatic Amino Acids. J. Am. Chem. Soc. 1966, 88, 693-696. (i) Leussing, D. L.; Hanna, E. M. Metal Ion Catalysis in Transamination. IV. Nickel(II) and Zinc(II)-GlyoxylateAmino Acid Complexes. J. Am. Chem. Soc. 1966, 88, 696-699. (j) Nakao, Y.; Sakurai, K.-I.; Nakahara, A. The Stability of Fused Rings in Metal Chelates. III. The Relative Stability of Copper(II) Complexes of Aldehyde- and Ketone-Schiff Bases. Bull. Chem. Soc. Jpn. 1966, 39, 1471-1476.

(22) Krebs, H. A. Equilibria in Transamination Systems. Biochem. J. 1953, 54, 82-86.

(23) Miller, S. L.; Magowan-Smith, D. The Thermodynamics of the Krebs Cycle and Related Compounds. J. Phys. Chem. Ref. Data, 1990 $19,1049-1073$.

(24) The reactivity ordering is in contrast to the one identified as optimal by Metzler for glyoxylate at $100{ }^{\circ} \mathrm{C}$ and $\mathrm{pH} 5\left(\mathrm{Cu}^{2+}, \mathrm{Al}^{3+}, \mathrm{Fe}^{3+}\right.$ and $\left.\mathrm{Fe}^{2+}\right) .{ }^{13 a}$ The optimal metals in our study are more similar to those identified by Mix for pyruvate at $70{ }^{\circ} \mathrm{C} .13 \mathrm{~b}$ 
(25) Gresser, M. J.; Tracey, A. S.; Parkinson, K. M. Vanadium(V) Oxyanions: The Interaction of Vanadate with Pyrophosphate, Phosphate, and Arsenate. J. Am. Chem. Soc. 1986, 108, 6229-6234.

(26) Rehder, D.; Weidemann, C.; Duch, A.; Priebsch, W. ${ }^{51}$ V Shielding in Vanadium(V) Complexes: A Reference Scale for Vanadium Binding Sites in Biomolecules. Inorg. Chem. 1988, 27, 584-587.

(27) Ferreira, C. M. H.; Pinto, I. S. S.; Soares, E. V.; Soares, H. M V. M. (Un)suitability of the use of $\mathrm{pH}$ buffers in biological, biochemical and environmental studies and their interaction with metal ions - a review. RSC Adv. 2015, 5, 30989-31003.

(28) (a) Rios, A.; Richard, J. P. Biological Enolates: Generation and Stability of the Enolate of N-Protonated Glycine Methyl Ester in Water J. Am. Chem. Soc. 1997, 119, 8375-8376. (b) Rios, A.; Amyes, T. L.; Richard, J. P. Formation and Stability of Organic Zwitterions in Aqueous Solution: Enolates of the Amino Acid Glycine and Its Derivatives. J. Am. Chem. Soc. 2000, 122, 9373-9385. (c) Rios, A.; Crugeiras, J.; Amyes, T. L.; Richard, J. P. Glycine Enolates: The Large Effect of Iminium Ion Formation on r-Amino Carbon Acidity. J. Am. Chem. Soc. 2001, 123, 7949-7950. (d) Toth, K.; Richard, J. P. Covalent Catalysis by Pyridoxal: Evaluation of the Effect of the Cofactor on the Carbon Acidity of Glycine. J. Am. Chem. Soc. 2007, 129, 3013-3021. (e) Crugeiras, J.; Rios, A.; Riveiros, E.; Amyes, T. L.; Richard, J. P. Glycine Enolates: The Effect of Formation of Iminium Ions to Simple Ketones on r-Amino Carbon Acidity and a Comparison with Pyridoxal Iminium Ions. J. Am. Chem. Soc. 2008, 130, 2041-2050. (f) Crugeiras, J.; Rios, A.; Riveiros, E. Richard, J. P. Substituent Effects on the Thermodynamic Stability of Imines Formed from Glycine and Aromatic Aldehydes: Implications for the Catalytic Activity of Pyridoxal-5'-phosphate. J. Am. Chem. Soc. 2009, 131, 15815-15824; (g) Crugeiras, J.; Rios, A.; Riveiros, E.; Richard, J. P. Substituent Effects on Electrophilic Catalysis by the Carbonyl Group: Anatomy of the Rate Acceleration for PLP-Catalyzed Deprotonation of Glycine. J. Am. Chem. Soc. 2011, 133, 3173-3183.

(29) The reason for the reduced conversion with the deuterated substrates is presently unclear, but prevents us from comparing the firstorder rate constants $k_{\mathrm{obs}}$ directly. Therefore, we decided to compare the initial rates of the reaction instead of the first-order rates.

(30) (a) For a detailed discussion of the kinetics of enolate protonation see the following review and the references cited therein: Keeffe, J. R.; Kresge, A. J. Kinetics and mechanism of enolization and ketonization. In The Chemistry of Enols; Rappoport, Z.; Ed.; Wiley: Chichester, UK, 1990; (b) Richard, J. P.; Amyes, T. L.; Toteva, M. M. Formation and Stability of Carbocations and Carbanions in Water and Intrinsic Barriers to Their Reactions. Acc. Chem. Res. 2001, 34, 981-988.

(31) Holleman, A.; Wiberg, N. Lehrbuch der Anorganischen Chemie. De Gruyter, 102 ed, 2007.

(32) Dixon, J. E.; Bruice, T. C. Comparison of the Rate Constants for General Base Catalyzed Prototropy and Racemization of the Aldimine Species Formed from 3-Hydroxypyridine-4-carboxaldehyde and Alanine. Biochemistry 1973, 12, 4762-4766.

(33) We assume that also for the vanadate-catalyzed reaction, formation/hydrolysis of the metal-chelate complexes is fast relative to the proton-transfer steps as shown by the presence of a primary KIE for the analogous reaction with glyoxylate (Figure 5).

(34) (a) Yu, H. S.; He, X.; Li, S. L.; Truhlar, D. G. MN15: A KohnSham global-hybrid exchange-correlation density functional with broad accuracy for multi-reference and single-reference systems and noncovalent interactions. Chem. Sci. 2016, 7, 5032-5051. (b) Weigend, F.; Ahlrichs, R. Balanced basis sets of split valence, triple zeta valence and quadruple zeta valence quality for $\mathrm{H}$ to Rn: Design and assessment of accuracy. Phys. Chem. Chem. Phys. 2005, 7, 3297-3305. (c) Marenich, A. V.; Cramer, C. J.; Truhlar, D. G. Universal Solvation Model Based on Solute Electron Density and on a Continuum Model of the Solvent Defined by the Bulk Dielectric Constant and Atomic Surface Tensions. J. Phys. Chem. B 2009, 113, 6378-6396. (d) For full details on the computational methods and the Gaussian reference, see the Supporting Information.

(35) Verma, P.; Truhlar, D. G. Status and Challenges of Density Functional Theory. Trends Chem. 2020, 2, 302-318

(36) (a) For a review see: Solís-Calero, C.; Ortega-Castro, J.; Hernández-Laguna, A.; Munoz, F. A comparative DFT study of the Schiff base formation from acetaldehyde and butylamine, glycine and phosphatidylethanolamine. Theor. Chem. Acc. 2012, 131, 1263; (b) Hine, J.; Via, F. A. Kinetics of the formation of imines from isobutyraldehyde and primary aliphatic amines with polar substituents. J. Am. Chem. Soc. 1972, 94, 190-194.

(37) Zuman, P. Die Reaktion der Karbonylverbindungen mit Primären Aminen. Collect. Czech. Chem. Commun. 1950, 15, 839-873.

(38) Zuman used polarography to determine the association constant for the reaction of pyruvate with glycinate $\left(K=2.47 ; \Delta \mathrm{G}^{0}=-2.2 \mathrm{~kJ}\right.$ $\left.\mathrm{mol}^{-1}\right)$ and with alanate $\left(K=0.93, \Delta \mathrm{G}^{0}=+0.2 \mathrm{~kJ} \mathrm{~mol}^{-1}\right)$. Richard reported on NMR titrations to study the reaction of phenylglyoxylate with glycine (with glycinate: $K=1.50, \Delta \mathrm{G}^{0}=-1.0 \mathrm{~kJ} \mathrm{~mol}^{-1}$; with the glycine zwitterion: $\left.K=(1.0 \pm 0.1) \times 10^{-4} \mathrm{M}^{-1}, \Delta \mathrm{G}^{0}=+22.8 \mathrm{~kJ} \mathrm{~mol}^{-1}\right) .28 \mathrm{~d}$

(39) Sørensen, P. E.; Bruhn, K.; Lindeløv, F. Kinetics and Equilibria for the Reversible Hydration of the Aldehyde Group in Glyoxylic Acid. Acta Chim. Scand. A. 1974, 28, 162-168.

(40) Anderegg, G.; Arnaud-Neu, F.; Delgado, R.; Felcman, J.; Popov, K. Critical Evaluation of Stability Constants of Metal Complexes of Complexones for Biomedical and Environmental Applications. Pure Appl. Chem. 2005, 77, 1445-1495.

(41) An experimental study of the effect of the buffer concentration on the reaction rate as done e.g. by Richard in refs. $28 \mathrm{~d}$,e is not possible in a straightforward way in our systems, as e.g. in the vanadate-catalyzed reaction the concentration of phosphate ions affects the formation of the vanadate/phosphate anhydride (Figure 2A).

(42) The role of metal ions as catalysts for deprotonation has been studied with e.g. $\mathrm{Zn}^{2+}$ : Crugeiras, J.; Richard, J. P. A Comparison of the Electrophilic Reactivities of $\mathrm{Zn}^{2+}$ and Acetic Acid as Catalysts of Enolization: Imperatives for Enzymatic Catalysis of Proton Transfer at Carbon. J. Am. Chem. Soc. 2004, 126, 5164-5173. 
TOC Graphic
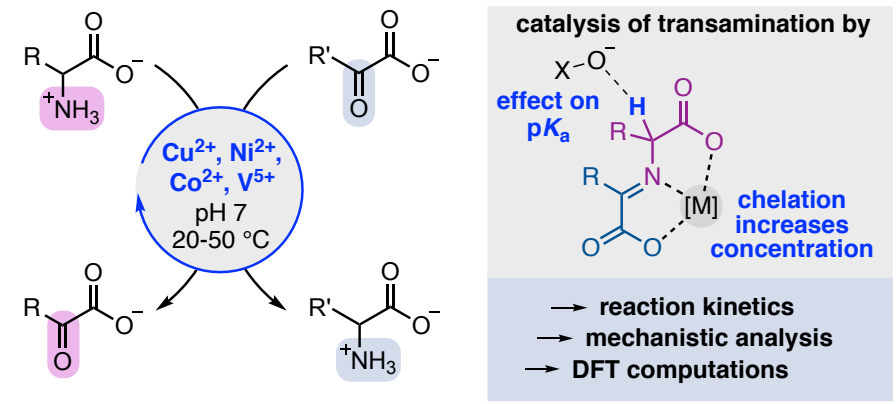